\title{
Growth and sectoral dynamics in the Italian regions
}

\author{
Raffaele Paci and Francesco Pigliaru \\ University of Cagliari and CRENoS \\ Via S. Ignazio 78, 09123 Cagliari, Italy \\ email:paci@unica.it_pigliaru@unica.it
}

\begin{abstract}
Regional differentials in per capita income and labour productivity in Italy is one of the most notable cases of regional inequality and have attracted attention from economists from all over the world since the 1950s.

In this paper we first aim at yielding a comprehensive description of the pattern of regional inequality in Italy on the basis of a new dataset on the main regional variables for the period 1951-94. We use descriptive statistics and panel regression analysis, in order to allow direct comparisons with the impressive evidence available on a large number of national cases. Second, we offer our contribution to the debate about the sources of the persistence of a high degree of regional inequality in Italy. We concentrate on sectoral dynamics in order to assess how much of the initially high potential for convergence due to the dualistic structure of the poorer regions has been exploited, by which regions, under what regional policy regimes.

Our analysis remarks that a limited convergence process has occurred over the years 1951-75; afterward the degree of inequality between Northern and Southern regions has increased again. Moreover, the regional distribution of per capita income presents a bimodal polarisation with a rich convergence club which includes most of northern regions, and a poor club made of a small group of non-adriatic southern regions.

In the sectoral analysis we find that dual mechanisms play a role in aggregate convergence as long as the outflows of labour from the low productivity agriculture of the poorer regions are a source of expansion of these regions' industrial sector. Once this migration from agriculture to industry ends in some of these regions, the impact of dualistic mechanisms on convergence weakens significantly. Industrialisation, or its failure, still appears to be the key to understand why some of the lagging regions converge and others do not.
\end{abstract}

JEL: O40, R11

Keywords: Regional growth, Convergence, Sectoral dynamics, Italy.

July 1998 


\section{Introduction *}

This paper deals with one of the most studied cases of regional inequality. Regional differentials in per capita income and labour productivity in Italy have attracted attention from economists from all over the world since the 1950s, when Myrdal (1957) used it as an example of cumulative causation [among others, Eckaus (1961), Chenery (1962), Lutz (1962)].

The characterising feature of the Italian case is that all measures of the economic gap between the average Southern region and the rest of the country have shown it to be remarkably persistent. Moreover, we do not have a full understanding yet of what is generating this persistence. The recent renewed attention to regional datasets spurred by the literature on convergence [Barro and Sala-i-martin (1995)] has further stimulated a long-standing discussion.

In this paper we first aim at yielding a comprehensive description of the pattern of regional inequality in Italy. The principal reason for doing this is that a new dataset on the main regional variables for the period 1951-94 was made available recently as the result of a major revision and update of the CRENoS data base (see the Appendix for more details). In this first part of the paper we use descriptive statistics and panel regression analysis of the kind widely used in the convergence debate, so that direct comparisons with other national cases is possible. In particular, we have added the national business cycle to the standard LSDV model to control for short term adjustments to transitory deviations from the trend output. We find that a limited convergence process occurred over the years 1951-75 for both per capita income and labour productivity. Afterward the degree of inequality between Northern and Southern regions has increased again. Moreover, the regional distribution of per capita income presents a bimodal polarisation where the rich convergence club

\footnotetext{
* This paper is part of the CRENoS research project on Regional disparities in Italy. We thank Nicola Pusceddu and Andrea Saba for valuable assistance in setting up the new and previous versions of CRENoS data banks, respectively. We gratefully acknowledge financial support from CNR P.S. "L'Italia verso l'Europa: Governance e politiche per lo sviluppo economico-sociale". This paper is forthcoming in J. Adams and F. Pigliaru, eds. (1998): Beyond Convergence. National and Regional Patterns of Growth and Change. Cheltenham: Edward Elgar.
} 
includes most of northern regions, while the poor club consists of a small group of non-adriatic southern regions.

Second, we offer our contribution to the debate about the sources of the persistence of a high degree of regional inequality in Italy. We concentrate on sectoral dynamics in order to assess how much of the initially high potential for convergence due to the dualistic structure of the poorer regions has been exploited, by which regions, under what circumstances (regional policy regimes included). We find that dual mechanisms play a role in aggregate convergence as long as the outflows of labour from the low productivity agriculture of the poorer regions are a source of expansion of these regions' industrial sector. Once this migration from agriculture to industry ends in some of these regions, the impact of dualistic mechanisms on convergence weakens significantly. Industrialisation, or its failure, still appears to be the key to understand why some of the lagging regions converge and others do not.

The paper is organised as follows. A description of the major characteristics of regional dynamics in Italy is in section 2. In section 3 we present our econometric analysis of the convergence process in 1951-94 and in various subperiods. In section 4 we analyse the sectoral dynamics and its interaction with aggregate convergence. Conclusions are in section 5.

\section{Disparities and mobility}

The aim of this section is to give a first overview of the "stylised facts" that have characterised the process of economic growth across the Italian regions since the post-war period.

A widely used measure of the degree of dispersion of a distribution is its coefficient of variation $(\mathrm{CV})$. Figure 1 reports the $\mathrm{CV}$ of per capita income and labour productivity within the twenty Italian regions (see the Appendix for the list). Considering the entire period 1951-94, it results that the dispersion at the beginning of the fifties was very high, particularly in terms of per capita income, and it has declined afterwards. Examining in more details the evolution over time, it 
clearly emerges that the most impressive reduction of the gap took place in a very limited period of time, 1960-75. On the other hand, over the last two decades the degree of regional disparities in Italy does not show any tendency to decline. As a matter of fact, the CV of both variables exhibits a slow tendency to increase and this divergence pattern appears stronger for the per capita measure.

More hints on the spatial source of the dispersion and on its temporal evolution come from Figure 2 which displays the $\mathrm{CV}$ within the two groups of north-centre and southern regions and also between them. Looking at labour productivity, it appears that the magnitude and the trend of the differential within the two groups of regions are very similar: a visible reduction until the end of the 1970s, a very low tendency to grow in the last decade. Consequently, the productivity gap between north and south has declined until the mid 1970s and then it has slightly increased.

The picture looks quite different if we observe the regional disparities in terms of per capita income. In such a case it is clear that almost all the reduction in the dispersion of the entire population comes from a process of convergence within the regions of the north-centre of Italy. The dispersion among these regions was very high at the beginning of the period $(\mathrm{CV}=0.35)$ but afterwards it has strongly decreased and it is now stable around a value of 0.09. On the other hand, the disparity among the southern regions was initially lower (0.14) and, despite some fluctuations over the period, it is now back to similar values. As a consequence, the north - south disparity shows a sharp fall in the 1960s and then a low and constant expansion in the last two decades. The conclusion is that the per capita income gap between north and south of Italy is still there, at the same level it was forty years ago, since most of the aggregate disparity fall results from an equalising process within northern regions.

A corroboration to these findings comes from the analysis of the top and bottom quartiles of the two distributions (Figure 3). The evolution of the per capita income index highlights how the overall decrease in the range depends totally on a reduction in the relative strength of the top four regions -- all located in the north of Italy -- rather than in an improvement of the bottom group of 
southern regions. On the other hand the convergence process in terms of labour productivity seems more spatially pervasive since it arises from both extremes of the distribution.

So far it has emerged that regional inequality is still a crucial characteristic of the Italian economic growth. On this regard, Paci and Saba (1998) have remarked how the Italian regional disparities are the highest among the European countries in terms of per capita income, while, considering labour productivity, Italy shows a degree of disparities lower than Spain and Greece. In short, the international comparison underlines further the persistence of the regional inequality in Italy.

An interesting element to be stressed is that - for both per capita income and labour productivity - in the mid seventies came to the end the within area convergence process. In other words in 1975 the degree of dispersion within the northern and southern regions has already declined to a level comparable to countries - like the United States - characterised by a very high factor mobility. The peculiarity of the Italian case seems to reside in the persistence of the abnormally high North—South differentials. We will return on this issue later.

Let now turn to the analysis of the shape of the distribution of per capita income and labour productivity and its change over time. A first description of this issue is provided in Figure 4 through the plot of the relative indices of the two variables in ascending order. ${ }^{1}$ Interestingly, the distributions of both per capita output and labour productivity become flatter over time, however their shapes show relevant differences. More precisely, the reduction in the dispersion of per capita income is mainly due to a relative decrease of the first richest quartile together with a growth of the second quartile. $^{2}$ At the same time the relative condition of the bottom poorest quartile has not significantly changed. The convergence process of labour productivity appears more evenly distributed across all

\footnotetext{
${ }^{1}$ Both distributions show a high peak for the richest region in 1951; this outlier is the small northern region of Valle d'Aosta.

${ }^{2}$ All regions in the first two quartiles are in the north-centre of Italy. Therefore this result confirms what we have previously remarked, that is the reduction in the overall income dispersion is mainly due to a convergence process among the northern and central Italian regions.
} 
groups of regions: the initially more productive regions have reduced their relative strength while the opposite trend has characterised the initially less efficient regions.

One of the hypothesis often put forward in the cross section growth literature is the existence of different "convergence clubs". To directly investigate this issue we have tested whether our two variables - per capita income and labour productivity - are normally distributed. Figure 5 reports the deviations from the normal distribution of the observed cumulative probability for 1994. The first result is that the deviations are very limited in the case of labour productivity. It means that the remaining regional dispersion, we have previously documented, tends to be normally distributed around the mean. A very different picture emerges when we examine the per capita income distribution. In this case it clearly turns out that the assumption of normality is violated since the distribution exhibits two peaks around the average. This bimodal polarisation process highlights the presence of two different convergence clubs in the per capita income distribution across the Italian regions. The first club includes most of the Northern rich regions, while the second is made by a small group of poor Mezzogiorno’s regions.

Let now consider the issue of mobility using the distribution dynamics matrices proposed by Quah (1993). For both labour productivity and per capita income, let consider four states characterised by an initially similar number of individuals in each state. ${ }^{3}$ Then we compute a transition matrix where the element $a_{i j}$ indicates the average probability of individuals included in state $i$ in the initial year to end in state $j$ in the final year (see Table 1).

Considering labour productivity over the entire period 1951-94 it emerges that the Italian regions are characterised by a high degree of mobility. It is worth noting that together with an upward mobility, we can also detect important phenomena of downward mobility. As much as $60 \%$

\footnotetext{
${ }^{3}$ The choice of the grid points is obviously arbitrary. We have followed the criteria of including a similar number of individual in each state while leaving the bounded state with the same width. As a result the grid points (as percentage of the Italian average) are: 70, 90, 110 for per capita income and 80, 95, 110 for labour productivity. We have also tried with different grid points but, although the numeric results are slightly different, the qualitative findings do not change.
} 
of regions with an initial productivity level greater than $110 \%$ of the Italian average, has shifted down in 1994, some of them even below the Italian average. At the same time $50 \%$ of the initially less efficient regions have improved their relative position. As a result of these up and down movements the distribution of labour productivity ends with the strong polarisation around the average that we have already pointed out. As a matter of fact, 15 out of 20 regions in 1994 are included in the quite narrow range $80-110 \%$ relative to the Italian average. However, it has to be remarked once more that the most intensive polarisation process has occurred over the 1951-75 period when $75 \%$ and $57 \%$ of the regions moved up respectively from the first and second state and also all the regions initially in the highest group have shifted down. As a result, $90 \%$ of the Italian regions were included in the two middle groups in 1975. Afterwards, the process of convergence to the middle states shows a weak tendency to decrease due to movements toward the extreme groups.

As regard to per capita income, it also shows a high degree of mobility from one state to another, especially in the upward direction. Notable examples of mobility are the $40 \%$ of regions initially included in the second poorest state that has moved in 1994 in the next two groups, and the $60 \%$ from the third to the fourth state. On the other hand, the richest group has maintained all its individuals (the entry in the main diagonal is unity). Considering the two sub-periods let remark that over the years 1951-75 (that is the period of stronger reduction of the income dispersion) the upward mobility of poorer regions is outstanding, $60 \%$ and $40 \%$ respectively for the first and second state. On the contrary, over the years 1975-93 it is remarkable the downward shift that occurred to the poorest group (67\%). Once more the final distribution of per capita income highlights the presence of two convergence clubs among the Italian regions: a poor club (with a share of 25\%) and a rich one $(45 \%)$, while the two average states are characterised by very low frequencies. 
From the analysis of the transition matrices it thus seems that the process of regional growth in Italy has been characterised by a high degree of individual mobility with relevant phenomena of catching up and falling behind. ${ }^{4}$

\section{Aggregate convergence}

In this section we investigate on the process of aggregate convergence across the Italian regions. This analysis has been commonly conducted using cross section regressions [see Barro and Sala-i-Martin (1995)]. From a Solow's model with Cobb-Douglas technology and exogenous saving rates and technological progress, the unconditional convergence process has been described by the following linear regression equation:

$$
\ln y_{i t}-\ln y_{i t-T}(1 / T)=a+b \ln y_{i t-T}+u_{i}
$$

where $y$ is, alternatively, GDP per capita or per worker.

According to this approach, there is absolute $\beta$-convergence if the coefficient $b<0$, that is if economies that were poorer at the beginning of the period are growing on average faster than richer ones. The idea of absolute convergence relies on the assumption that the only difference across economies is their initial level of capital per worker. However it is common practice to add in eq. (1) a set of dummy variables to control for unobservable effects that differ among individuals (level of technology, propensities to save, infrastructures, public policies, etc.). This approach leads to the so called conditional $\beta$-convergence. Obviously there are limitations to the number of individuals we can control for, so that we have to rely on the implicit assumption that groups of individuals (regions, countries) are affected in the same way by the left out variables. ${ }^{5}$

\footnotetext{
${ }^{4}$ Examples of individual mobility in the relative distribution are initially wealthy regions that decline (Piemonte), together with initially poor that also decline (Sardegna); moreover there are regions that grow, starting either from medium (Veneto) or very low (Abruzzo) positions.

${ }^{5}$ For instance in the international literature a common way is to group together the African countries or the OECD or the OPEC ones. In cross regions regressions we may assume that regions within the same countries are affected in the same way by the unobservable variables, so that we can control just including a set of national dummies.
} 
An alternative way is to test the existence of the convergence process by means of panel estimation. ${ }^{6}$ The panel formulation has the advantage that it allows us to control for the unobservable variables for each single individual in our population. As for the time span to be chosen, equation (1) can be interpreted as an approximation of the transitional dynamics of the system around its steadystate, so that there are no a priori reasons in favour of one particular choice [Islam (1995)]. As a consequence, there is no uniformity in the literature about which time span is more appropriate for convergence analysis [see Islam (1995) and Evans and Karras (1996)]. In our dataset, estimations based on the longest time span (cross-section data) and on the shortest one (annual panel data) yield very similar results with respect to the few key questions we are considering here (especially, the length of the period characterised by absolute convergence and the significance of the dummies controlling for groups of regions). In the following, we report the annual panel data estimations. Clearly, the use of annual data poses several problems -- see Evans and Karras (1996), Durlauf and Quah (1998) and de la Fuente (1998) -- one of which is that business cycle fluctuations may create disturbances in the estimates, a point that we will discuss presently. One way to estimate convergence with a panel of annual data is the following:

$$
\ln y_{i t}-\ln y_{i t-1}=a+b \ln y_{i t-1}+d_{i}+d t+v_{i t}
$$

where $v_{\mathrm{it}}$ is an error term with zero mean which varies across regions and years; $d_{\mathrm{i}}$ are regional effects included to control for region-specific unobservable variables; $d_{\mathrm{t}}$ are time effects that should control for short-term time fluctuations common to all regions. In other words the temporal dummies are supposed to capture the effect of the national business cycle. The following analysis confirms this.

We have estimated separately the national business cycle as the residuals of the regression of the Italian growth rate of $y_{\mathrm{t}}$ with respect to a time trend. In Figure 6 those residuals are plotted

\footnotetext{
${ }^{6}$ A panel model of the convergence process among the Italian regions has been estimated by Di Liberto (1994), Boltho et al. (1998) and Cellini and Scorcu (1997). The results of these studies are not directly comparable with ours since they used different specifications, periods and data sets.
} 
together with the time effects estimated in eq. (2). As expected, the correlation between the Italian business cycle and the time effects is positive and highly significant for both per capita GDP and labour productivity. Therefore, a more parsimonious and economically meaningful version of eq. (2) can be obtained by substituting the 43 time dummies required there with the national business cycle variable $(\mathrm{BC}){ }^{7}$ So our final specification of the convergence equation to be estimated over the period 1951-1994 is ${ }^{8}$ :

$$
\ln y_{i t}-\ln y_{i t-1}=a+b \ln y_{i t-1}+d_{i}+B C_{t}+v_{i t}
$$

The regression results are reported in Table 2 and 3 for labour productivity and per capita income, respectively. For each variable we have estimated the convergence process for the entire period and for two sub-periods 1951-75 and 1975-1994. ${ }^{9}$ Moreover, for each period, we first report the LSDV results (regr. 1), with the business cycle and the regional effects. In regr. 2 and 3 we include two dummy variables, DS and DA, to test the hypothesis that southern and Adriatic regions moved towards a common steady state (obviously, in these specifications the fixed regional effects are not included). ${ }^{10}$ We also report the estimates based on a simple pooling in order to assess the robustness of our results. Regr. 4 includes only the initial level of the dependent variable, while in regr. 5 the business cycle is added.

\footnotetext{
${ }^{7}$ The use of the time dummies instead of BC yields results that are qualitatively similar to those presented below.

${ }^{8}$ Our estimations are based on a Least Squares Dummy Variables (LSDV) model. The fixed effect formulation has been preferred over the random one since we assume that the individual effects are correlated with the exogenous variables. Indeed, this assumption seems quite reasonable since it implies that the unobservable variables, which are reflected by the individual effects, are correlated with the level of GDP per capita (or per worker) in each region. Moreover, since in panel regression we may have problems of both autocorrelation and heteroscedasticity, we have estimated the model with cross section weights. In this formulation the observations with smaller variances receive a larger weight and thus have greater influence in the computed estimates. However, the standard LSDV model yields results very similar to those presented here .

${ }^{9}$ We have identified 1975 as the break year since, as we have remarked in the previous section, in the mid seventies the process of reduction in the regional dispersion came to a halt.

${ }^{10}$ The existence of a specific growth pattern among the Mezzogiorno's region is a well known and widely studied issue in the literature on economic development in Italy. More recently several studies have focused on the positive growth of the so called "third Italy" which includes the Italian regions on the Adriatic sea. On this see the original contribution by Bagnasco (1977). The distinction between Adriatic and non -Adriatic regions seems particularly fruitful to analyse the growth differentials among the southern regions, as we will show in section 4.3.
} 
Considering labour productivity (Table 2), the growth rate appears negatively and significantly affected by its lagged levels over the entire period examined. However, the explanatory power of the model increases considerably only when the business cycle is included. As expected, the national business cycle turns out to be positive, signalling a general increasing trend of the productivity growth rate in Italy. The magnitude of the coefficient of $\mathrm{y}_{\mathrm{t}-1}$ results quite stable in all the different specifications of the model, showing a speed of the convergence process around $2.3-2.5 \%$ per year. The dummy for the Mezzogiorno's regions is negative and significant, it means that the steady state level for this group of regions is lower than the average. On the other hand, an above the average equilibrium level characterises the Italian regions belonging to the successful Adriatic belt. The specifications without fixed effects confirm these results, although the explanatory power of the model turns out to be quite small when only the lagged level of labour productivity is included.

Once more the analysis of the growth process over different period of time allows to point out crucial differences. Indeed an absolute convergence process seems to have occurred only in the first period considered, 1951-1975 (regr. B.4). Afterwards, the coefficient of the lagged productivity level is not significant (regr. C.4). Moreover, the role of the regional fixed effects and geographical dummies is quite negligible in the first period: their inclusion does not alter the value of the convergence coefficient and DS and DA are not even significant. In short, until 1975, regional growth in Italy was characterised by a strong convergence process towards a common steady state level as it was already pointed out in the descriptive analysis of Section 2. On the other hand, the last two decades tends to be dominated by local convergence processes: the geographical dummies are remarkably significant (regr. C.2 and C.3) and the coefficient of $y_{t}$ reaches its maximum (regr C.1). We will try to give some explanations on the mechanisms and causes of these processes in the next section. 
Let now turn our analysis to per capita income. As we have already remarked, this variable can yield results which differ from those based on labour productivity whenever participation and unemployment rates are not constant over time and across regions.

The econometric analysis confirms the existence of an unconditional convergence process limited to the 1951-75 period (regr. B4 in Table 3), while the coefficient of the $y_{t}$ in the period 197594 is not significant (regr. C4). Even in the post-war years, the annual speed of convergence for per capita income $(1.4 \%)$ appears quite lower than for productivity. Another difference with respect to labour productivity is that now DS and DA are significant in both sub-periods. This result confirms the relevance of local factors (mainly the regional differences in the labour market) which distinguish the growth process of per capita income and thus the tendency towards different convergence clubs.

\section{Sectoral dynamics and convergence}

As we have seen, absolute convergence in labour productivity was a strong phenomenon up to 1975 , then came to a halt. In section 2 we have seen that part of this pattern is due to the fact that large part of the high initial dispersion of labour productivity across non Southern regions was eliminated by 1975 (see Figure 2, A), so that the potential for convergence within this subgroup had been largely exploited by then. The second component of the slow down of convergence is of a different nature. The convergence between the Southern regions and the others ends in 1975, when the degree of inequality is still remarkably high compared with those prevailing both in other European nations and in the USA [Paci and Saba (1998), Sum and Fogg (1998)]. Therefore, in the following we concentrate on this second more puzzling component.

Several explanations have been put forward to address it. As Boltho et al. (1998) show, many of such explanations focus on the failure of the remarkable effort made by the Italian state to obtain a sustainable industrialisation of the Southern regions through active regional policies [Sylos Labini (1985), Giannola (1982), Graziani (1978)]. 
One aspect worth noticing is that, implicitly, this type of interpretation suggests that the sectoral mix and the mechanisms behind its changes -- either market-driven or policy-induced -- are crucial for convergence analysis. Implicitly again, this interpretation sheds doubts on the usefulness of aggregative models to identify at least some of the factors generating the observed dynamics of regional productivity differentials.

We share these doubts, and think that we can obtain a more complete picture of the troubled history of the Italian regional problem by taking explicitly into account the sectoral dynamics underling the process. In this section, our specific contribution to this line of research is twofold.

First, we sum up a methodology proposed in Paci and Pigliaru (1997a) to assess the impact of structural change on regional growth rates, and the main result we obtained by applying it to the Italian dataset. Second, we investigate whether industrialisation in the Southern regions is indeed important to understand the pattern of the convergence process, and the role played by policy to obtain industrialisation. To assess such a role, first of all we need to define what market mechanisms were expected to generate an expansion of industry in poorer and mostly agricultural regions, and how strong they have been in reality. To proceed along these lines, we use a simple model of the dual economy to obtain testable hypotheses concerning the relationship between sector composition and convergence in a cross-section of economies.

\section{1. $\beta$-convergence and/or structural change}

Our first task is to test whether the impact of structural change on regional growth in Italy is compatible with the neoclassical growth model. The two-sector version of Solow's growth model requires, in general, that aggregate growth is the result of a capital-deepening process taking place in all sectors of the economy, so that convergence should be detected within each of them. As a consequence, when we use cross-section data to estimate the convergence equation, levels and 
changes in sectoral weights may contribute to account for growth differentials, but we should still find a significantly negative role played by the variable measuring initial productivity levels. ${ }^{11}$

To test whether the initial productivity level remains significant and negative when structural change is controlled for, Paci and Pigliaru (1997a) has suggested that a measure of the impact on the aggregate growth rate of the sectoral composition and its change for each region should be included in the standard cross-section convergence equation. When we apply this methodology to the case of the Italian regions we find that -- contrary to what the solovian framework would predict -- the coefficient of the initial value of productivity turns out to be not significant, while sectoral composition and structural change exert the expected positive effect on the convergence process. ${ }^{12}$

Sectoral shifts seem therefore to be a crucial factor to explain the convergence pattern in Italy. Closer inspection of the data suggests that the convergence-enhancing structural change was of the type one would expect to take place in dual economies. Indeed, further evidence in Paci and Pigliaru (1997a) shows that Southern regions in 1970 were still characterised by large agricultural weights, and that a fast decline of those weights in favour of the industrial sector took place during the period 1970-75 -- when aggregate convergence was strong. After that period, that specific mechanism came to a halt and this -- not surprisingly -- was accompanied by a halt of the whole convergence process.

Taken together, this evidence suggests the usefulness of considering more explicitly the mechanisms of the dual economy in order to test their relevance for the convergence process across the Italian regions, their overall strength, their dependence on regional policies.

\footnotetext{
${ }^{11}$ For the exception to this general rule, recall Rybczynski's theorem [Rybczynski (1955)]. This theorem deals with a case in which growth in the overall capital-labour ratio is associated with stability of the sectoral ratios. However, the conditions required by the theorem apply exclusively to the very special case of a small country facing the world market [for a recent use of this feature, see Ventura (1996)] - i.e., is not relevant to the analysis of convergence across a finite number of regional economies.
}

${ }^{12}$ See Table 2 regr. 2.2 in Paci and Pigliaru (1997a, p. 308). 
4.2. Convergence and the dual economy

Let us start considering the market mechanisms characterising a closed neoclassical dual economy, the main assumption of which are as follows [Mas Colell and Razin (1973)]. The agricultural good is for consumption only, while the second good, the "non agricultural" one, is both a consumption and the investment good of the economy. The saving rate is exogenous as well as the proportion of the non agricultural good used for consumption. Full employment and perfect intersectoral factor mobility are also assumed. Production in both sectors takes place using physical capital and labour, with a Cobb-Douglas constant returns to scale technology. In this economy, the sectoral capital-labour ratios turn out to be a constant proportion of the aggregate capital-labour ratio.

The dualistic feature of this system is that differences in the sectoral values of marginal productivity are not instantaneously equalised. Equalisation takes time, with workers moving from agriculture, where the lower wage is paid, to the other sector according to a migration rate which is an increasing function of the wage differential. Since migration flows cause the wage gap to diminish, then the rate of growth of the non agricultural labour share is a negative function of the level of the same variable $(\rho)$. As for the dynamics of the aggregate capital-labour ratio $k$, it is possible to show that:

(4) $\frac{\dot{k}}{k}=\phi\left(\frac{k}{\rho}\right)^{\beta-1}$

where $\phi$ is a positive constant and $\beta$ is the exponent of capital in the Cobb-Douglas technology. This dual economy converges towards a unique and globally stable steady-state with the values of $\rho *$ and $k^{*}$ depending on the parameters of the model [Mas Colell and Razin (1973)].

One interesting feature of this dual economy is obtained by totally differentiating (4) and rearranging in order to obtain: 


$$
\frac{d(\dot{k} / k)}{d \rho}=\omega k^{\beta-1} \rho^{-1}\left(1-\frac{\dot{k} / k}{\rho / \rho}\right)
$$

where $\omega$ is another positive constant. The sign of (5) is positive for small values of $\rho$, since the growth rate of $\rho$ is higher than that of $k$. Therefore we have a phase in which capital-deepening occurs at an accelerating rate. As the transition to the steady-state proceeds, the difference between the two growth rates decreases, since $\rho / \rho$ decreases and $k / k$ increases, and eventually is reversed. Once this is accomplished, $k / k$ starts declining.

This result allows us to obtain testable hypotheses about the relationship we should observe in a cross-section of similar economies between the growth rates of labour productivity and the initial levels of the non agricultural labour share. In general, assuming that technological knowledge is uniform across all economies (on this more below), larger values of $\rho$ exert a negative direct effect on the growth rate of $y$ - small $\rho$ s imply fast growth of the sector which produces the investment good. However, there is also an indirect effect operating through the influence of $\rho$ on capital accumulation, so that when the values of $\rho$ are small enough, $k / k$ increases with $\rho$. These two effects exert opposing influences on productivity growth for the smaller values of $\rho$, while they exert a common negative influence for the remaining range of the values of $\rho$. Therefore, as we show in Paci and Pigliaru (1997b), a cross-section of similar economies distributed along a common transitional path should generate a relationship between the growth rate of labour productivity and the value of $\rho$ which either takes the inverted $U$ shape which characterises capital accumulation, or is monotonically negative. 
Before proceeding, a final point about the model should be noticed. The transition to the steady-state is characterised by the fact that for any given value of $\rho$, the higher is $k$ and $y$, the lower the growth rate of these variables [see eq. (4) above]. This implies that in our regressions on the relationship between the growth rate of productivity and $\rho$, we should control for the level of $y$, the coefficient of which is expected to be negative.

\subsection{Evidence}

Our first step is to find confirmation that the basic mechanism of a dual economy is at work in our case study - i.e., that significant flows of labour migration from agriculture to the non agricultural sector take place during the period. Moreover, we need to control whether intersectoral migration acquires the pattern postulated by the model, with the growth rate of the non agricultural share being a decreasing function of its level.

A pattern of this type is indeed what we find in our data, as shown in Figure 7; the correlation between growth rates and levels is -0.94 for the whole period $1960-94^{13}$. Moreover, this pattern is remarkably stable. No significant differences were found by dividing the whole period in two subperiods, 1960-75 and 1975-94, with the correlation in both periods constant at -0.94 .

Another feature of our dataset is that the share of the non agricultural level and the level of total labour productivity are strongly correlated $(-0.85)$ - as one should expect to be the case in a cross-section with a number of dual economies.

Turning to our econometric evidence, the results of panel data regressions with fixed (regional) effects and temporal dummy variables are in Table $4^{14}$. No inverted U relationships have been detected in our estimations (these results are not reported) so that the relationship between the

\footnotetext{
${ }^{13}$ In this section the initial year is 1960 since sectoral data at the regional level are not available for the 1950 s.

${ }^{14}$ Substituting the temporal dummies with the business cycle variable used in section 3 would not alter substantially the results in Table 4.
} 
variable measuring the non agricultural share and the growth rates was expected to be monotonically negative. This prediction is corroborated by regr. 1 for the whole period under investigation. The negative sign is significant at the $1 \%$ level in the absence of the lagged value of aggregate labour productivity. When we add the latter, estimations are likely to be affected by the high correlation between the two explanatory variables in our dataset. However, we have enough variation unique to each of the two variables to be able to identify the signs of their coefficients, with the coefficient of the sectoral share still bearing the expected negative sign (regr. 2).

This outcome yields further evidence that the aggregate convergence process is linked to changes in sectoral weights which are consistent with the working of a dual economy ${ }^{15}$. However, this link appears to be rather weak over the whole period.

As for subperiods, we use 1975 to split the whole period since the process of absolute convergence ended that year. In regression 3 we tested the stability overtime of the coefficient of the non agricultural sector share NAS (the dummy-slope DNAS is equal to NAS for the period 1960-75, and to zero for the period 1976-94). The result is that the coefficient is significantly negative in the first subperiod (1960-75), while it is not significant in 1976-94. An explanation for this could be that intersectoral migration ends in the second subperiod, or that its intensity is no longer inversely related with the shares of the non agricultural sector. However, we have already noticed that such an inverse relationship is stable and significant in both subperiods, so that we rule this first hypothesis out, and conclude that it is not the expansion of the "non agricultural" sector as a whole in the poorer regions that seems to work in favour of convergence.

A second hypothesis about the observed different impact of that expansion on growth is that important changes took place in the underlying sectoral dynamics. One a priori factor in favour of this hypothesis is that in the mid 1970s the regional policy focused on mobilising direct manufacturing investment in the South weakened significantly. If the pattern of industrialisation in 
the South was significantly influenced by this type of policy, and was positive for convergence, this should emerge from the analysis of the two subperiods ${ }^{16}$.

Our disaggregated data for the two subperiods corroborate this hypothesis. Figure 8 shows the relationship between rates of change and levels of the industrial share in the two subperiods. Contrary to the case of the non agricultural sector, here the correlation between rates of change and levels is far from constant -- it was equal to -0.68 in 1960-75 and dropped to a statistically non significant -0.27 in 1975-94. This pattern is unique of industry. The other component of the non agricultural sector -- services -- shows relationship between rates of change and levels which is both strong and stable across subperiods (with correlation coefficients equal to -0.82 and -0.83 respectively)

In the case of the industrial sector, it is important to notice that one reason behind the low correlation recorded in 1975-94 is that four of the poorer and still little industrialised regions (Sicily, Sardinia, Calabria, Campania) saw the rate of change of their industrial share turn from positive to negative, while it remained positive for the other four Southern regions (Abruzzo, Molise, Basilicata, Puglia), who are conventionally considered being part of the so-called Adriatic belt.

Does this different pattern of the process of industrialisation in the Southern regions explain part of their growth performances? While we do not offer exhaustive evidence on this important question, some evidence pointing to a positive answer is shown in Figure 9, where the straight lines correspond to the averages of the regions' growth rates measured along the axes. In 1960-75 all Southern regions achieved faster than average growth rates of both labour productivity and industrial share (with the partial exception of Campania). In 1975-94 the Southern group is neatly split, with

\footnotetext{
${ }^{15}$ A similar result was found by Paci and Pigliaru (1997b) for the regions of the European Union.

${ }^{16}$ Using an annual panel for the period 1960-1991, Di Liberto (1994) finds for the whole period that the variable measuring investment in machinery and equipment is significantly positive in convergence regressions. The role of this type of investment in explaining the North-South gap in per capita GDP is analysed by Boltho, Carlin, Scaramozzino (1998). Finally, Paci and Pusceddu (1994) found a positive influence of the financial incentives made available by the Italian regional policy on the growth process of the Southern regions.
} 
Sicily, Sardinia, Calabria, and Campania experiencing a faster than average decline of their industrial shares accompanied by a slower than average productivity growth. On the contrary, the remaining Southern regions were characterised by high rates of both industrial expansion and productivity growth.

To conclude, we sum up our main findings. First, dual mechanisms play a role in aggregate convergence as long as the outflows of labour from the low productivity agriculture of the poorer regions are a source of expansion of these regions' industrial sector. Once this migration from agriculture to industry ends in some of these regions, the impact of dualistic mechanisms on convergence weakens significantly. ${ }^{17}$

Second, regional policy is likely to have accelerated industrialisation of Southern regions in the initial phases. Starting from mid-seventies the public intervention became much less favourable to industrialisation in the Mezzogiorno, both directly and indirectly, as much of the literature on the Mezzogiorno has pointed out [Del Monte and Giannola (1997)]. Directly, because investment in the South by State-controlled large manufacturing enterprises and funding for financial incentives to private investment diminished dramatically. Indirectly, because in the second subperiod public intervention aimed at sustaining income levels in the South allowed a faster than average expansion of the public sector share ${ }^{18}$. Indeed, over the period 1960-75 the pattern of expansion of the non market service sector in the poorer regions was on average in line with the rest of the country. Interestingly, the second subperiod yields a different picture. In all Southern regions but one (Sardinia), this sector's rate of change is significantly higher than average. In other words, while the flows of labour out of agriculture were initially linked with industrialisation in most of the poorer

\footnotetext{
${ }^{17}$ This evidence confirms and extends some of the findings about sectoral dynamics and convergence discussed in Paci and Pigliaru (1997a). Moreover, the catching up effect of the sectoral shifts from agriculture to high productivity sectors for the case of the European regions is remarked in the contribution by Paci and Pigliaru (1998) in this volume.

18 As for the econometric evidence in previous studies, a number of correlations between growth rates and several measures of the share of public expenditure in GDP have been reported by Di Liberto (1994), and by Paci and
} 
region, later they were accompanied by faster than average expansion of the non market services in the same regions -- with some of them who simultaneously experienced a decrease of their (small) industrial share.

From the viewpoint of the model used above, the first of these findings is broadly consistent with its main prediction. For the sake of simplicity, models of the dual economy generally assume that all labour exiting the agricultural sector translates into an expansion of "industry" -- the sector producing the capital good. This is the reason why we expect poorer regions to grow faster in the transition to the steady-state. In reality, several elements not explicitly included in the model can weaken the realisation of this predicted outcome. Among them, the existence of non market sectors, and the influence exerted by policy decisions on their weight, can be an important source of distortion of the sectoral allocation of productive factors. In some circumstances, the role of such sectors in a region's growth performance may be radically different from -- and less growthenhancing than -- the one postulated for the industrial sector by the dual model.

The second finding is likely to raise more fundamental questions. The model predicts that, in the absence of distortionary policies, market mechanisms should suffice for an expansion of industry in the lagging regions to take place. However, the period in which this phenomenon does occur is also the period of active regional policy. So one possibility is that the specific market mechanisms considered by the model were not enough to trigger industrialisation. Again, several reasons can be listed to account for this discrepancy between theory and reality. Among them, we would like to underline the following one -- while the model discussed in this section assumes uniformity of technology across regions, localised aspects of knowledge accumulation may exist and make that assumption inadequate even in the case of regional economies. In particular, if technological knowledge is not continuously uniform across space, we would expect its diffusion mechanisms to

Pigliaru (1995). The evidence in this latter paper shows that in 1970-89 the convergence process is affected positively by a measure of the stock of public infrastructures and negatively by public consumption. 
cause well defined spatial patterns within the convergence process ${ }^{19}$. For instance, the existence of one of these patterns might be signalled by the significance of the Adriatic dummy in our regressions in section 3. The presence of localised aspects of technological knowledge may also help explaining the different long-run impact of the policies aimed at industrialising the South. One possibility is that these policies were successful in those areas where mechanisms of technology diffusion from CentreNorthern regions were stronger.

More generally, industrialisation, or its failure, still appears to be the key to understand why some of the lagging regions converge and others do not.

\section{Conclusions}

In this paper we have analysed the Italian regional growth in the last four decades using several descriptive statistics and panel regression analysis. Moreover, we have specifically investigated on sectoral dynamics in order to assess how much of the initially high potential for convergence due to the dualistic structure of the poorer regions has been exploited, by which regions, under what policy regimes.

As far as per capita income is concerned our analysis has shown that a limited convergence process occurred over the years 1951-75; afterward the degree of inequality between Northern and Southern regions has increased again. As a result, the regional distribution of per capita income presents a bimodal polarisation where the rich convergence club includes most of northern regions, while the poor club consists of a small group of non-adriatic southern regions.

Considering labour productivity, from our results it emerges that a process of absolute convergence took place across Italian regions up to 1975 , and then it came to a halt. Such pattern has involved all territorial areas and is caused by two main components. First, the potential for convergence of the initially medium income regions of the Centre-North was largely exploited by

\footnotetext{
${ }^{19}$ Pattern of this kind have been detected by Quah (1996) for the European regions.
} 
mid-seventies. Second, part of the Southern regions' large potential for converging was exploited up to 1975 through a process of sectoral shift from low to high productivity sectors. Since then, however, an important divide became evident -- four out of eight Southern regions experienced a relative slow down of growth and an halt of their process of convergence, in spite of the fact that they were still lagging remarkably behind the Centre-Northern regions; in the other Southern regions convergence did not stop in 1975.

A sectoral dimension lies behind this second component. The large weight of a backward agriculture sector characterising all the Southern regions in the 1950s translated in a sustained process of industrialisation (and of convergence) only in some of them. For the Southern regions, being (un)successful in convergence coincides with being (un)successful in expanding the industrial sector. Future research should address the problem of what has originated the neatly distinct performances of industrialisation across groups of regions, how important the mechanisms of technology diffusion have been, what policies have been effective and why. 
References

Adams J. and Pigliaru F. (eds.) (1998) Beyond Convergence. National and Regional Patterns of Growth and Change. Cheltenham: Edward Elgar.

Bagnasco A. (1977) Tre Italie. La problematica territoriale dello sviluppo italiano. Bologna: il Mulino.

Barro R. and Sala-i-Martin X. (1995) Economic growth. New York: Mc Graw-Hill.

Boltho A., Carlin W. and Scaramozzino P. (1998) Will East Germany become a new Mezzogiorno?, in Adams J. and Pigliaru F. (eds.).

Cellini R. and Scorcu A. (1997), How many Italies? What data show about growth and convergence across Italian regions, 1970-91, Rassegna di lavori dell'ISCO, 14, 93-124.

Chenery H. (1962) Politiche di sviluppo per l'Italia meridionale. Milano: Giuffrè.

de la Fuente A. (1998) What kind of regional convergence? CEPR WP, n.

Del Monte A. and Giannola A. (1997) Istituzioni economiche e Mezzogiorno. Roma: NIS.

Di Liberto A. (1994) Convergence across Italian regions, Nota di lavoro, 68.94, Fondazione Eni Enrico Mattei.

Durlauf S. and Quah D. (1998), The new empirics of economic growth, Centre for Economic Performance Discussion Paper no. 384.

Eckaus R. (1961) The North-South differential in Italian economic development, Journal of Economic History, 20, 285-317.

Evans P. and Karras G. (1996) Do economies converge? Evidence from a panel of US states, Review of Economics and Statistics, 78, 384-88.

Giannola A. (1982) Industrializzazione, dualismo e dipendenza economica del Mezzogiorno negli anni ‘70, Economia Italiana, 4, 65-90.

Graziani A. (1978) The Mezzogiorno in the Italian economy, Cambridge Journal of Economics, 2, 355-372.

Islam N. (1995) Growth empirics: a panel data approach, Quarterly Journal of Economics, 110, 1127-1170.

Lutz V. (1962) Italy. A study in economic development. London: Oxford University Press.

Mas-Colell A. and Razin A. (1973) A model of intersectoral migration and growth, Oxford Economic Papers, 25, 72-79.

Myrdal G. (1957), Economic theory and the underdeveloped regions. London: Duckworth.

Paci R. and Pigliaru F. (1995) Differenziali di crescita nelle regioni italiane: un'analisi cross-section, Rivista di Politica Economica, 85, 3-34.

Paci R. and Pigliaru F. (1997a) Structural change and convergence: an Italian regional perspective, Structural Change and Economic Dynamics, 8, 297-318.

Paci R. and Pigliaru F. (1997b) Is dualism still a source of convergence in Europe? Contributi di Ricerca CRENoS, 97/5.

Paci R. and Pigliaru F. (1998) European regional growth: Do sectors matter?, in Adams J. and Pigliaru F. (eds.). 
Paci R. and Pusceddu N. (1994) Intervento pubblico, industrializzazione e crescita delle regioni del Mezzogiorno, Studi Economici, 54, 67-95.

Paci R. and Saba A. (1998) The empirics of regional economic growth in Italy, 1951-1993, forthcoming in Rivista Internazionale di Scienze Economiche e Commerciali.

Quah D. (1993) Galton's fallacy and tests of the convergence hypothesis, Scandinavian Journal of Economics, 95, 427-443.

Quah D. (1996) Regional convergence cluster across Europe, European Economic Review, 40, 951958.

Rybczynski T. (1955) Factor endowments and relative commodity prices, Economica, 22, 336-341.

Sum A. and Fogg N. (1998) Inequality in regional and state per capita incomes in the U.S.: How much convergence has taken place?, in Adams J. and Pigliaru F. (eds.).

Sylos Labini P. (1985) L'evoluzione economica del Mezzogiorno negli ultimi trenta anni, Temi di discussione, Servizio Studi Banca d'Italia, n.46.

Ventura J. (1996), Growth and interdependence, Quarterly Journal of Economics, 112, 57-84. 
Appendix

In 1997 the Italian Statistical Office (ISTAT) published the new Regional Accounts for the period 1980-94 using a more accurate methodology to account for the unofficial sectors of the economy. Similarly, ISTAT reviewed the National Accounts for the period 1970-1995. Consequently, CRENoS has updated the data base presented in Paci and Saba (1998) embodying the new available information. We have obtained homogeneous series for the entire period 1951-94 by linking the earlier regional data to the new national and regional official ISTAT series. All monetary variables have been calculated in constant values at 1990 prices by means of regional and sectoral deflators. CRENoS data base is available under request.

Primary sources of regional data for the period 1951-1979.

Gross Domestic Product and Value Added:

- 1951-62, Tagliacarne G., Moneta e Credito, Banca Nazionale del Lavoro, 1961-65;

- 1963-69, UNIONCAMERE, I Conti Economici Regionali, Milano: Franco Angeli, 1972;

- 1970-79, SVIMEZ, I conti del Centro-Nord e del Mezzogiorno nel ventennio 1970-1989, Bologna: il Mulino, 1993;

Units of labour:

- 1951-59, ISTAT, Occupazione in Italia negli anni 1951-65, Supplementi straordinari al Bollettino Mensile di Statistica;

- 1960-69, ISTAT, Occupati per attività economica e regione 1960-1970;

- 1970-79, SVIMEZ, op. cit.;

Deflators:

- 1951-59, cost of living index at regional level, ISTAT, Annuario Statistico Italiano, Bollettino Mensile di Statistica, 1951-61;

- 1960-69, index of consumption prices at the regional level, Padoa Schioppa (1988);

- 1970-79, price index of GDP and Value Added at the regional and sectoral level, SVIMEZ, op. cit..

Regions. The letter in parentheses indicates the inclusion of each region in a group: NorthCentre (N), South (S), Adriatic (A).

$\begin{array}{llllll}\text { PIE } & \text { Piemonte } & (\mathrm{N}) & \text { MAR } & \text { Marche } & \text { (N)(A) } \\ \text { VDA } & \text { Valle D'Aosta } & (\mathrm{N}) & \text { LAZ } & \text { Lazio } & (\mathrm{N}) \\ \text { LIG } & \text { Liguria } & (\mathrm{N}) & \text { CAM } & \text { Campania } & (\mathrm{S}) \\ \text { LOM } & \text { Lombardia } & (\mathrm{N}) & \text { ABR } & \text { Abruzzo } & \text { (S, A) } \\ \text { TAA } & \text { Trentino Alto Adige } & (\mathrm{N}) & \text { MOL } & \text { Molise } & \text { (S, A) } \\ \text { VEN } & \text { Veneto } & (\mathrm{N}) \mathrm{A}) & \text { PUG } & \text { Puglia } & \text { (S, A) } \\ \text { FVG } & \text { Friuli Venezia Giulia } & (\mathrm{N})(\mathrm{A}) & \text { BAS } & \text { Basilicata } & (\mathrm{S}) \\ \text { EMR } & \text { Emilia Romagna } & (\mathrm{N})(\mathrm{A}) & \text { CAL } & \text { Calabria } & (\mathrm{S}) \\ \text { TOS } & \text { Toscana } & (\mathrm{N}) & \text { SIC } & \text { Sicilia } & (\mathrm{S}) \\ \text { UMB } & \text { Umbria } & (\mathrm{N}) & \text { SAR } & \text { Sardegna } & (\mathrm{S})\end{array}$




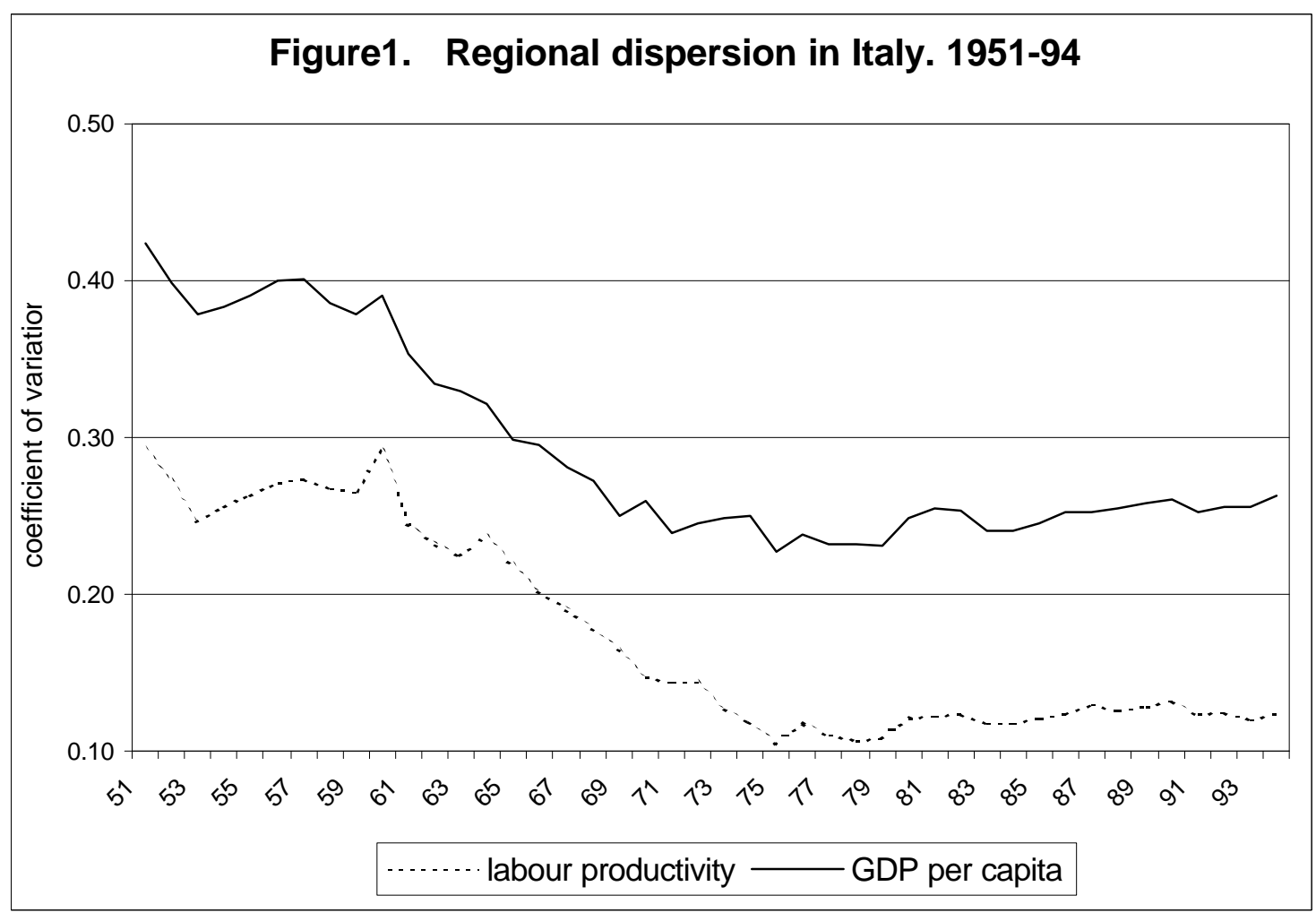


Figure 2. Dispersion across groups of Italian regions. 1951-94
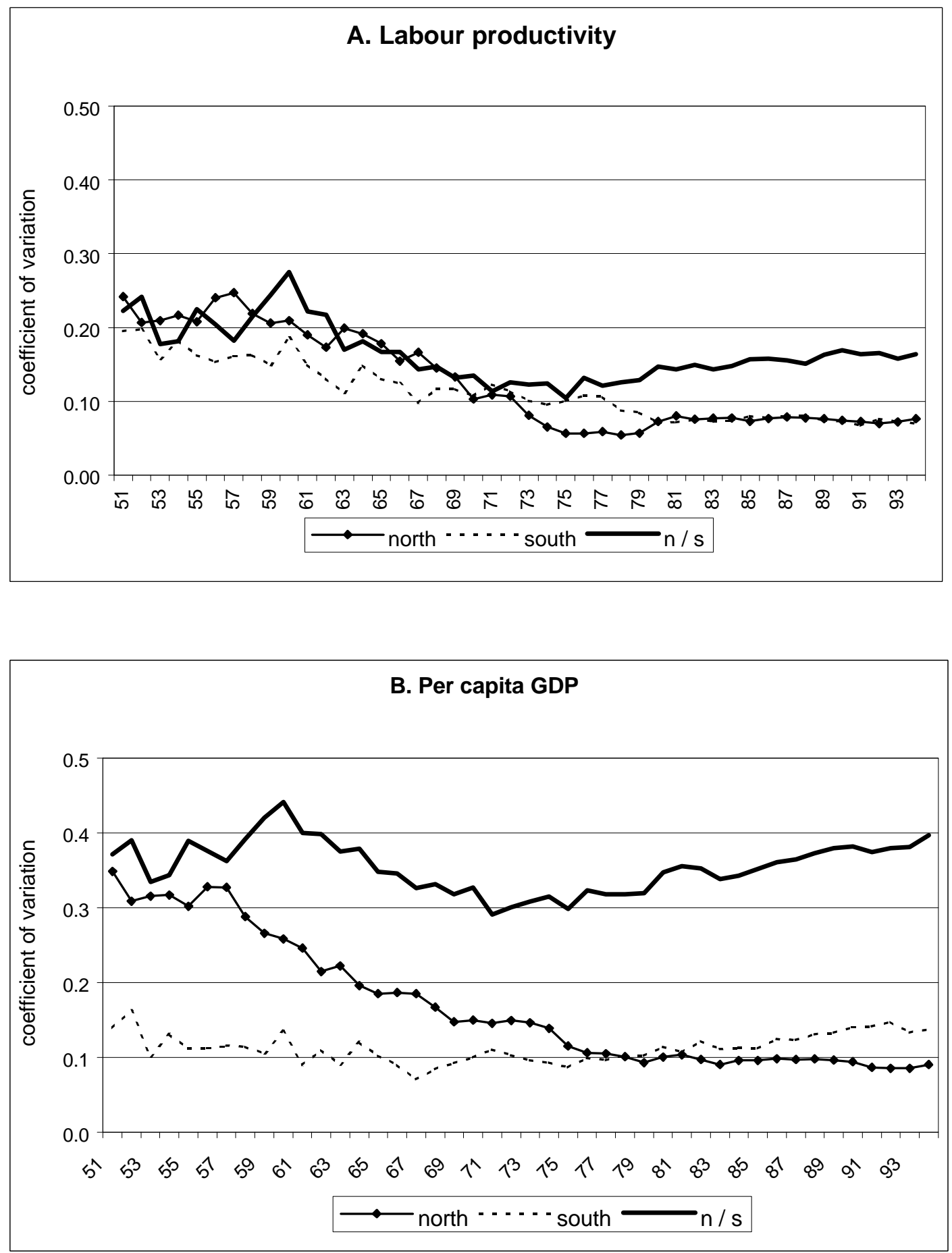


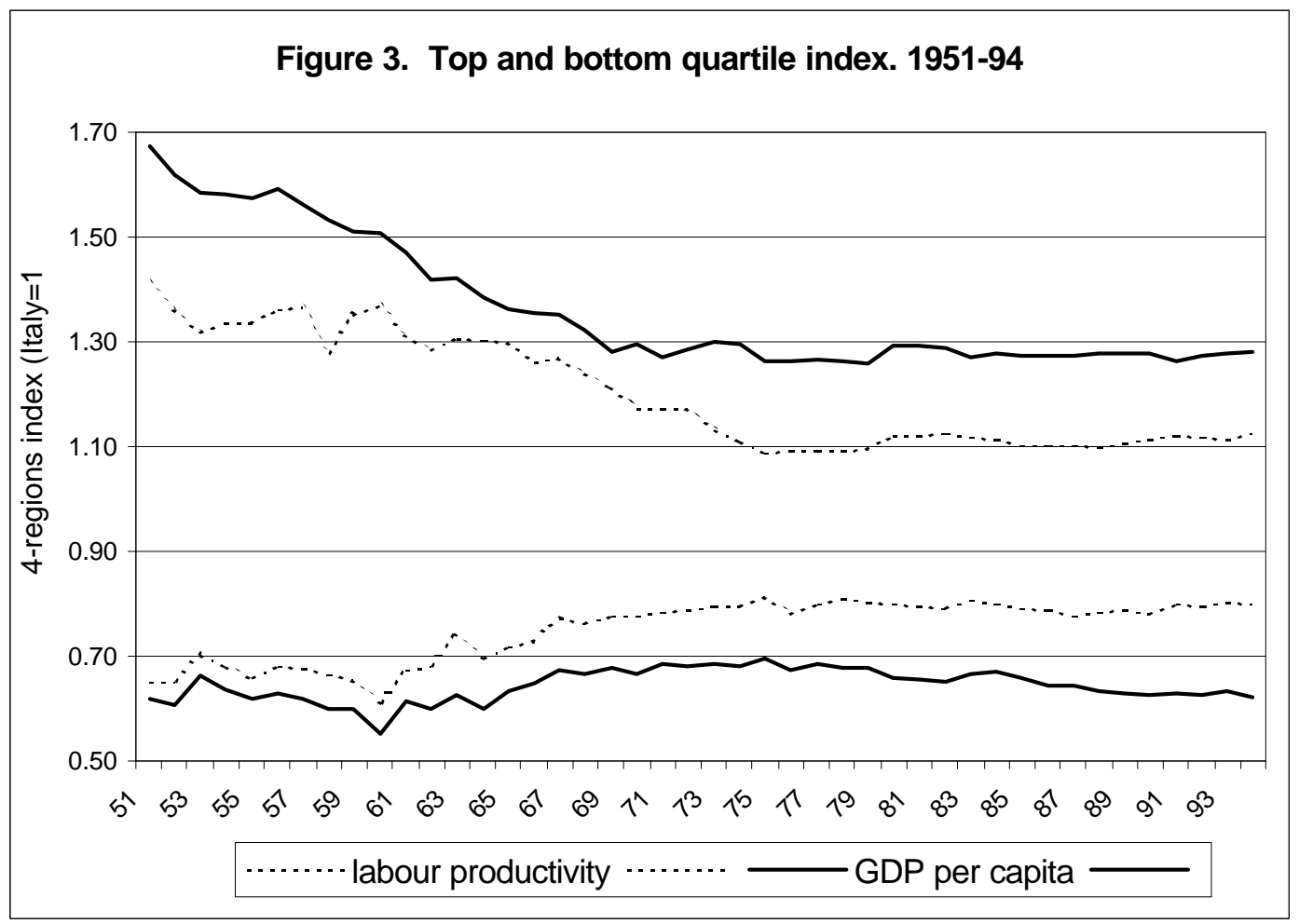


Figure 4. The shape of the distribution.
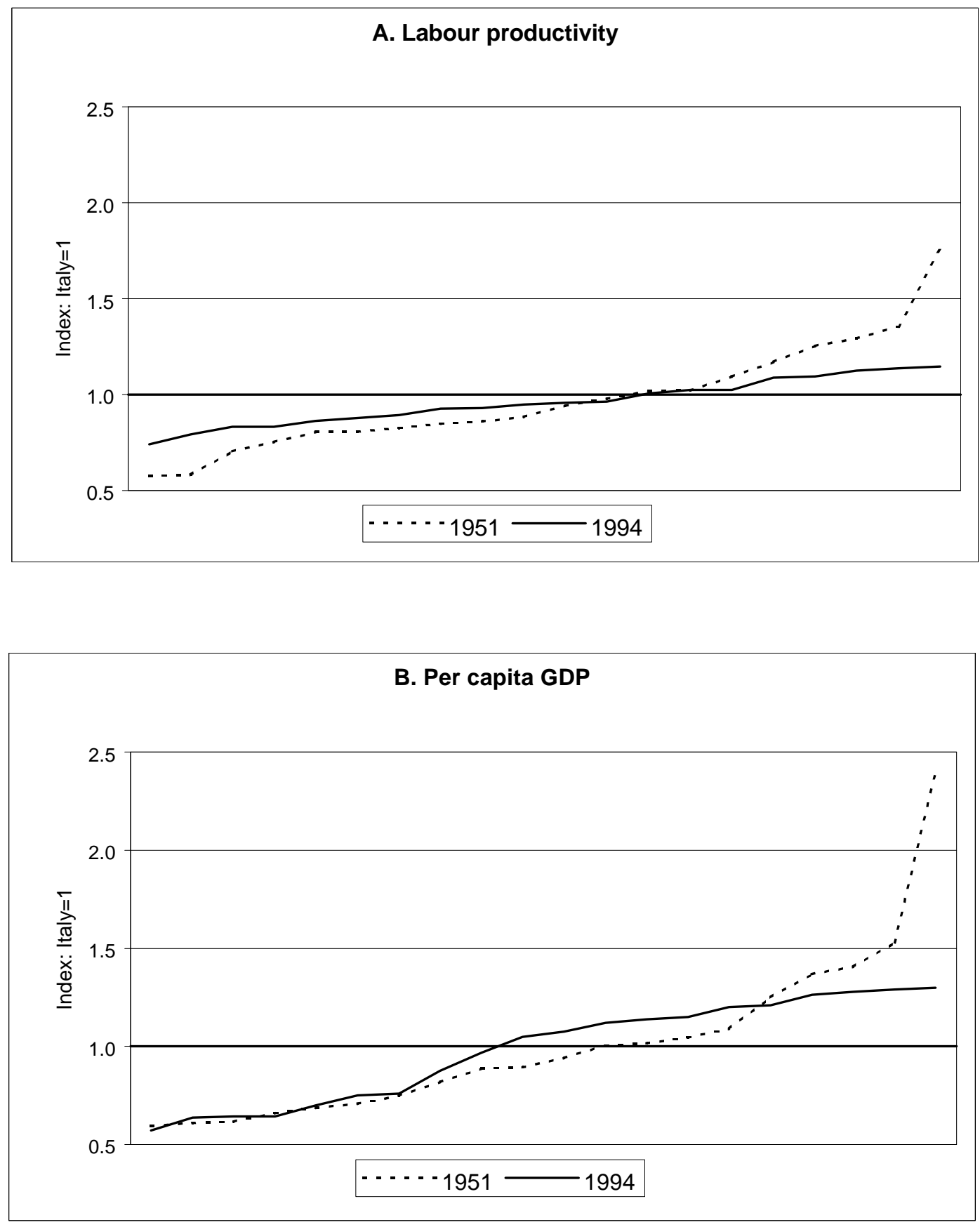
Figure 5. Test for normality in the distribution of GDP across the Italian regions. 1994

A. Labor productivity

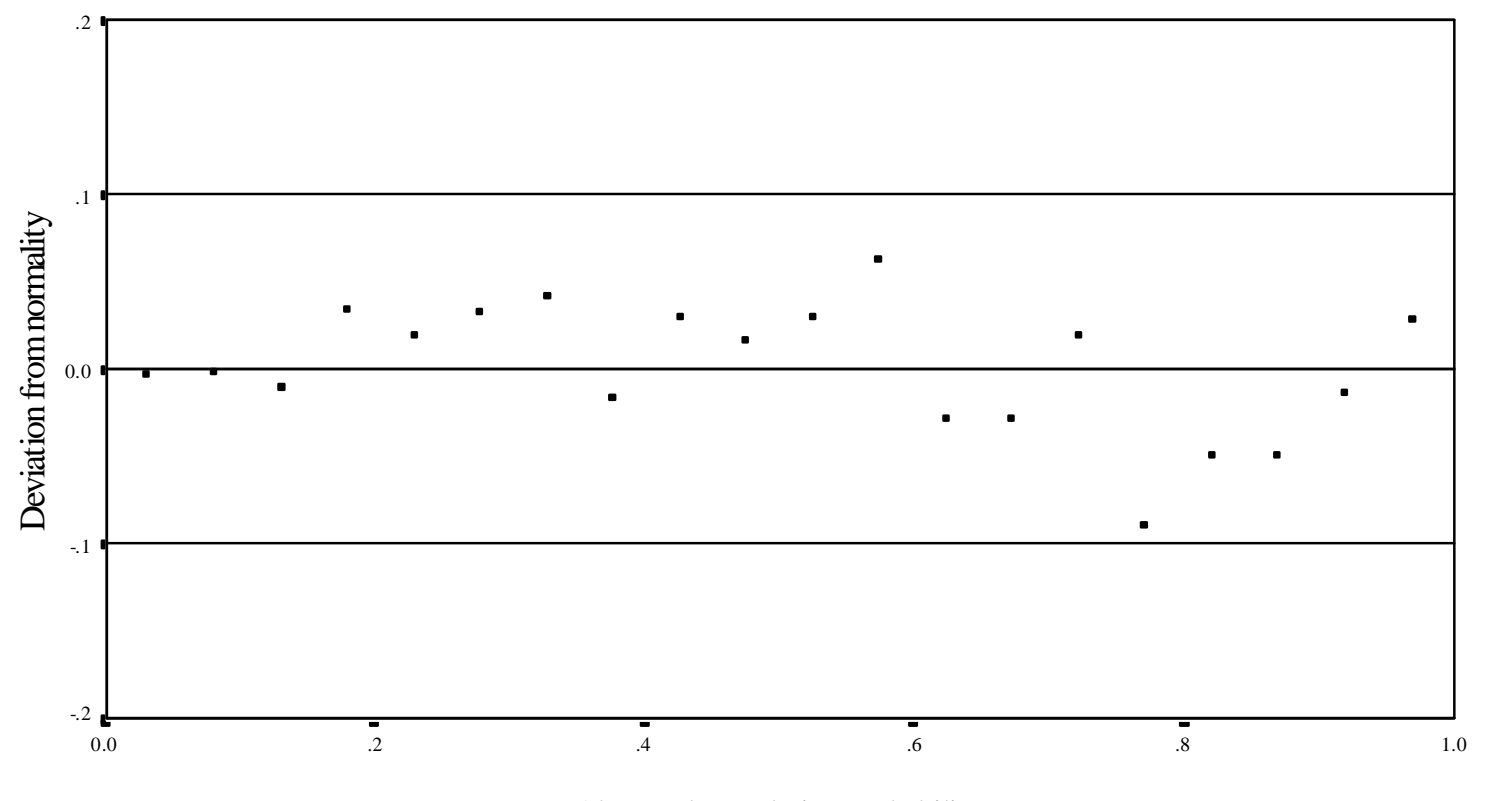

Observed cumulative probability

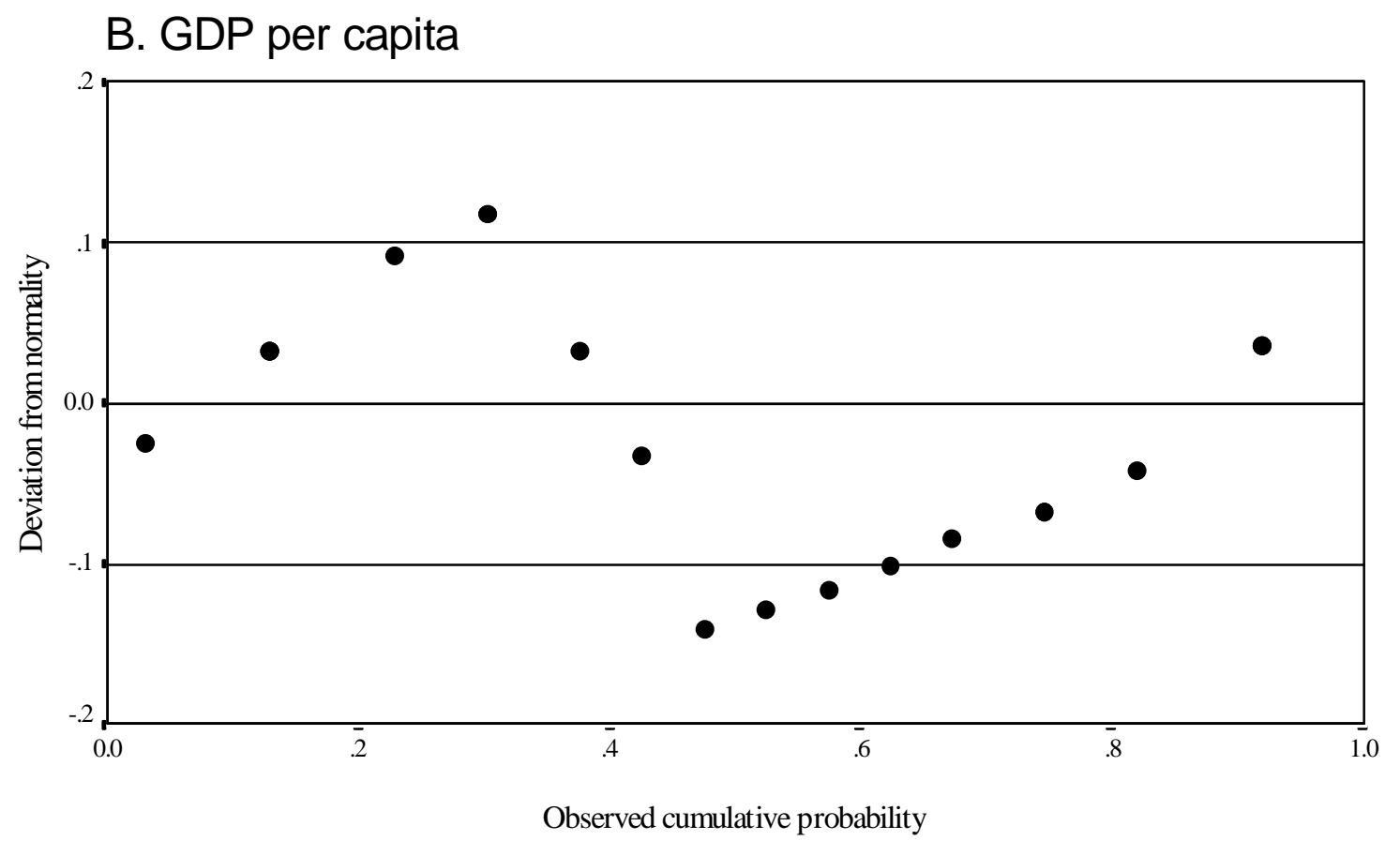


Figure 6. National business cycle and temporal fixed effects. 1951-94
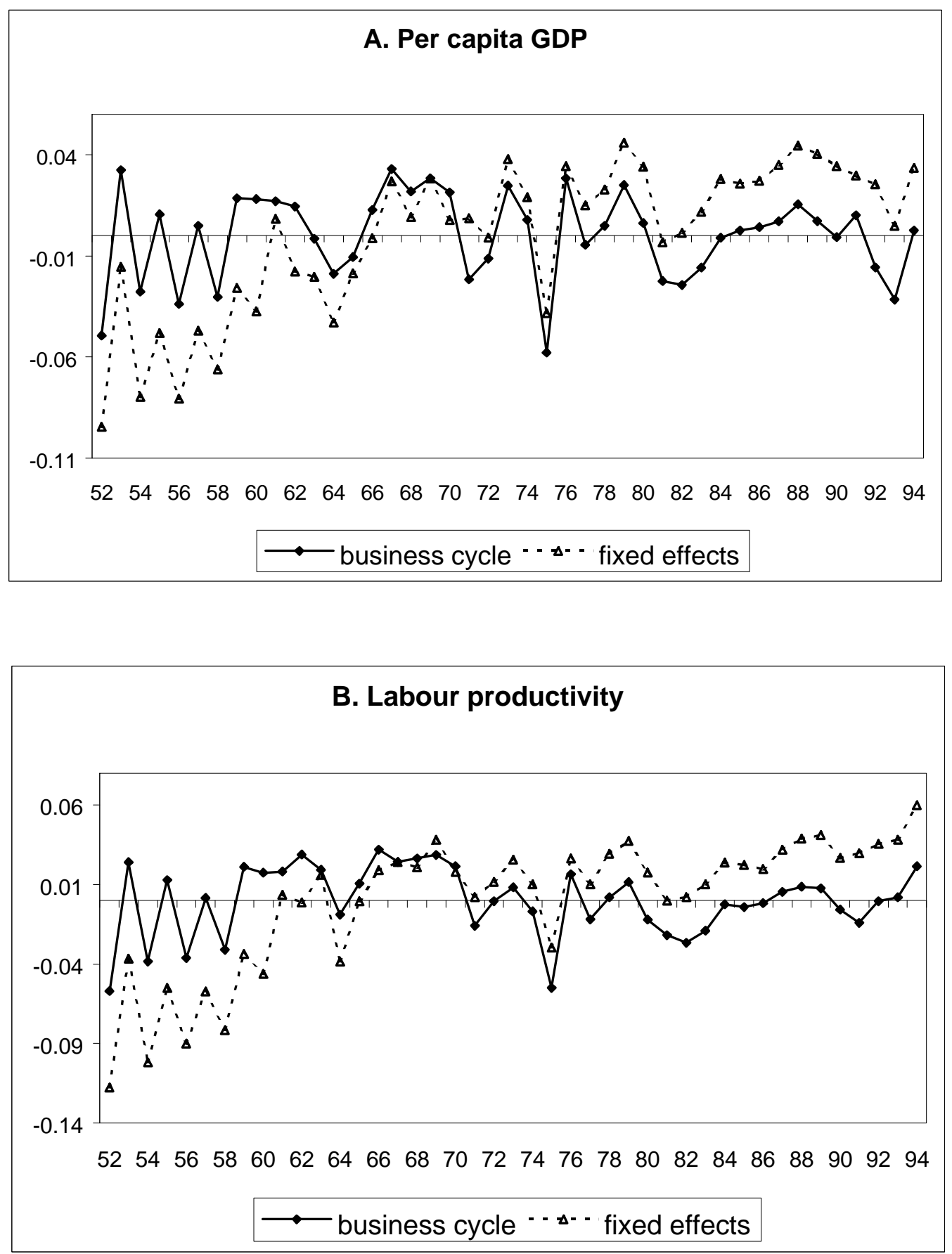
Figure 7. Non agricultural labour share and its changes. 1960-94

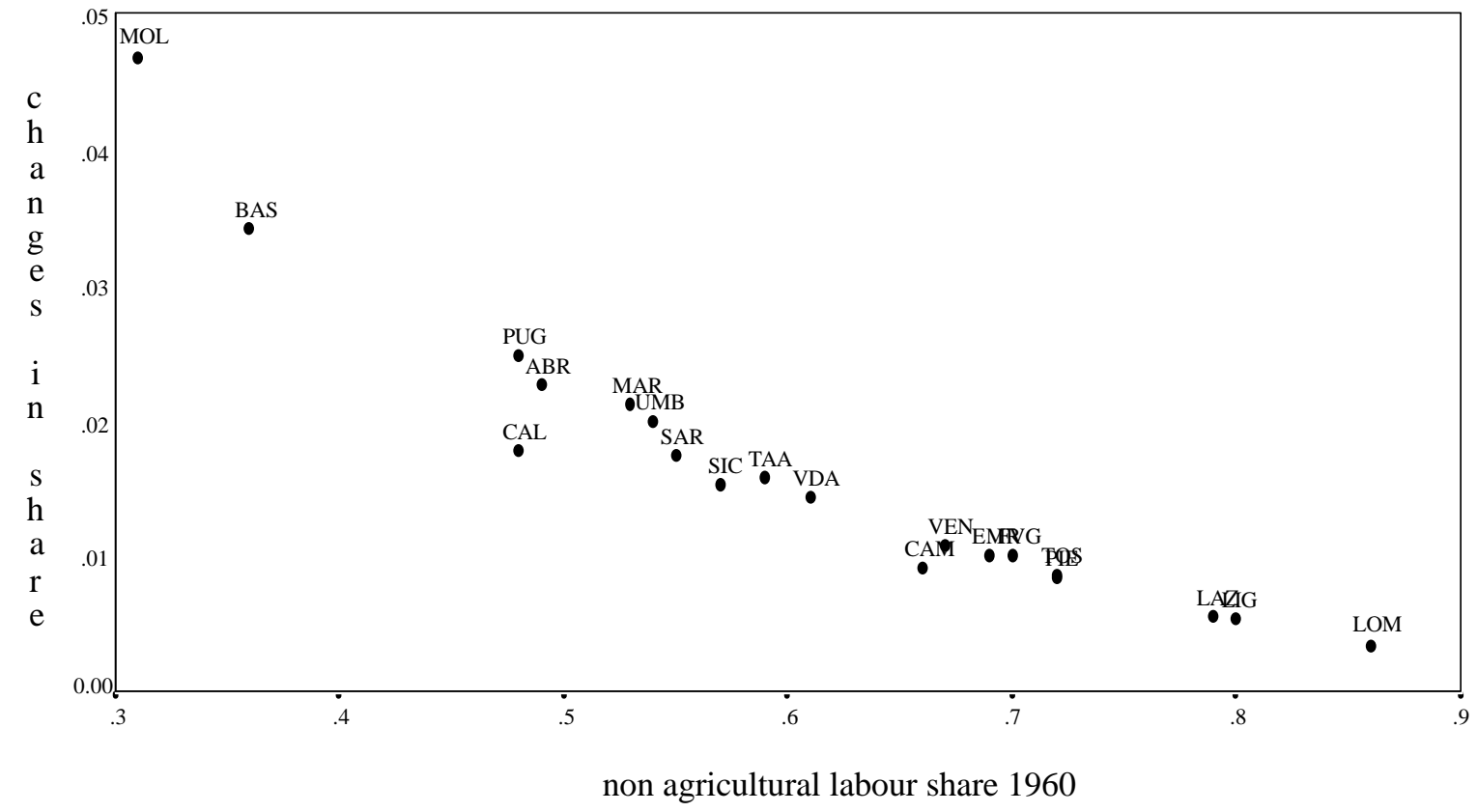


Figure 8. Industrial labour shares and its changes.

A. $1960-1975$

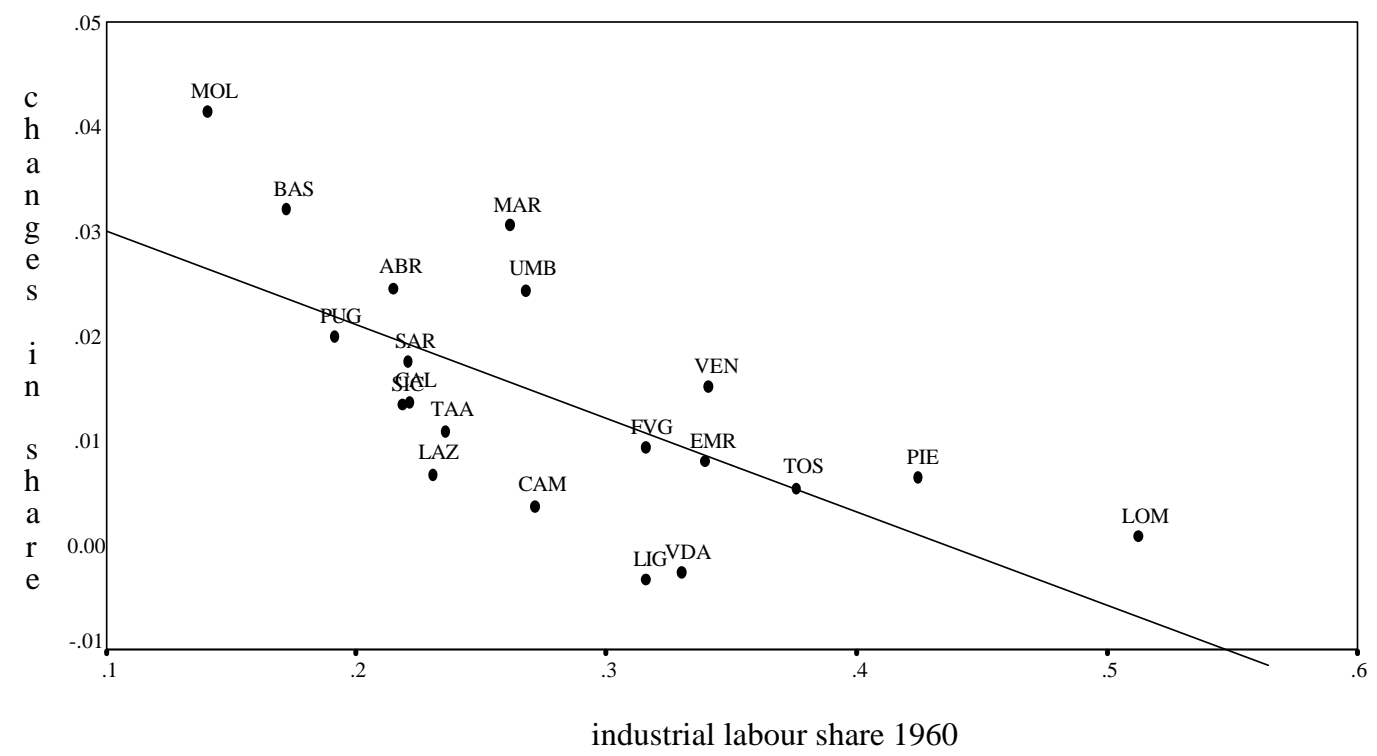

B. 1975 - 1994

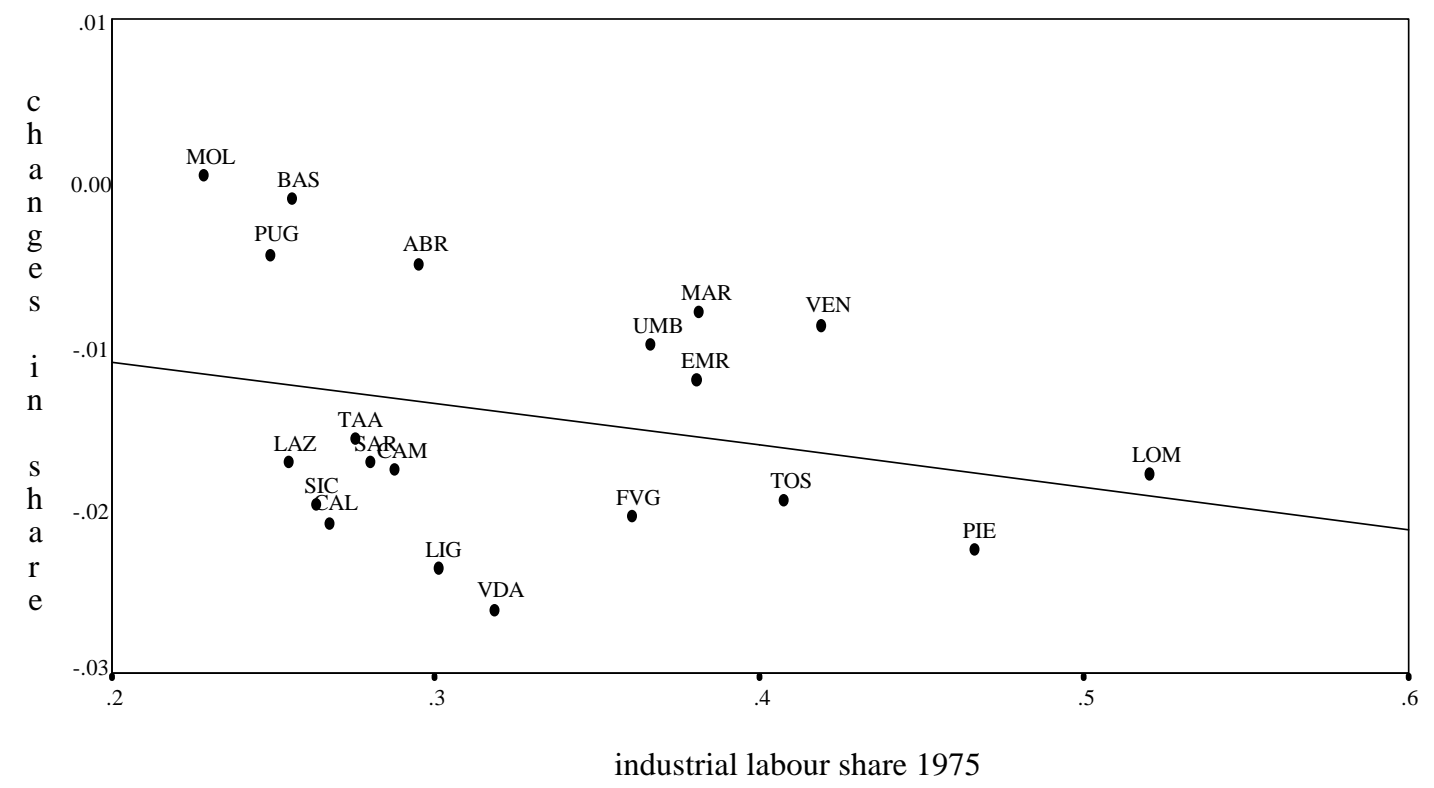


Figure 9. Growth of aggregate labour productivity and industrial share.

A. $1960-1975$

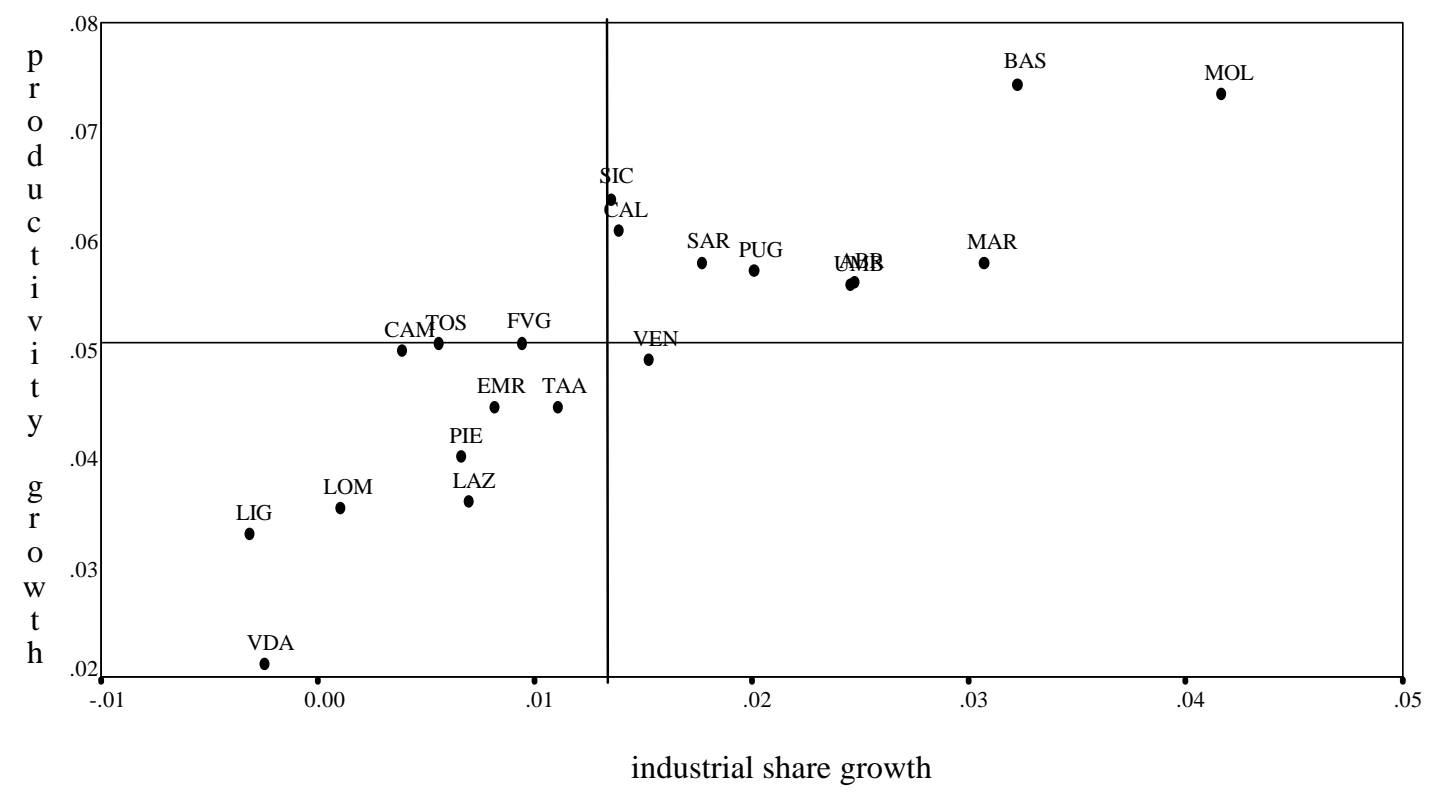

B. 1975 - 1994

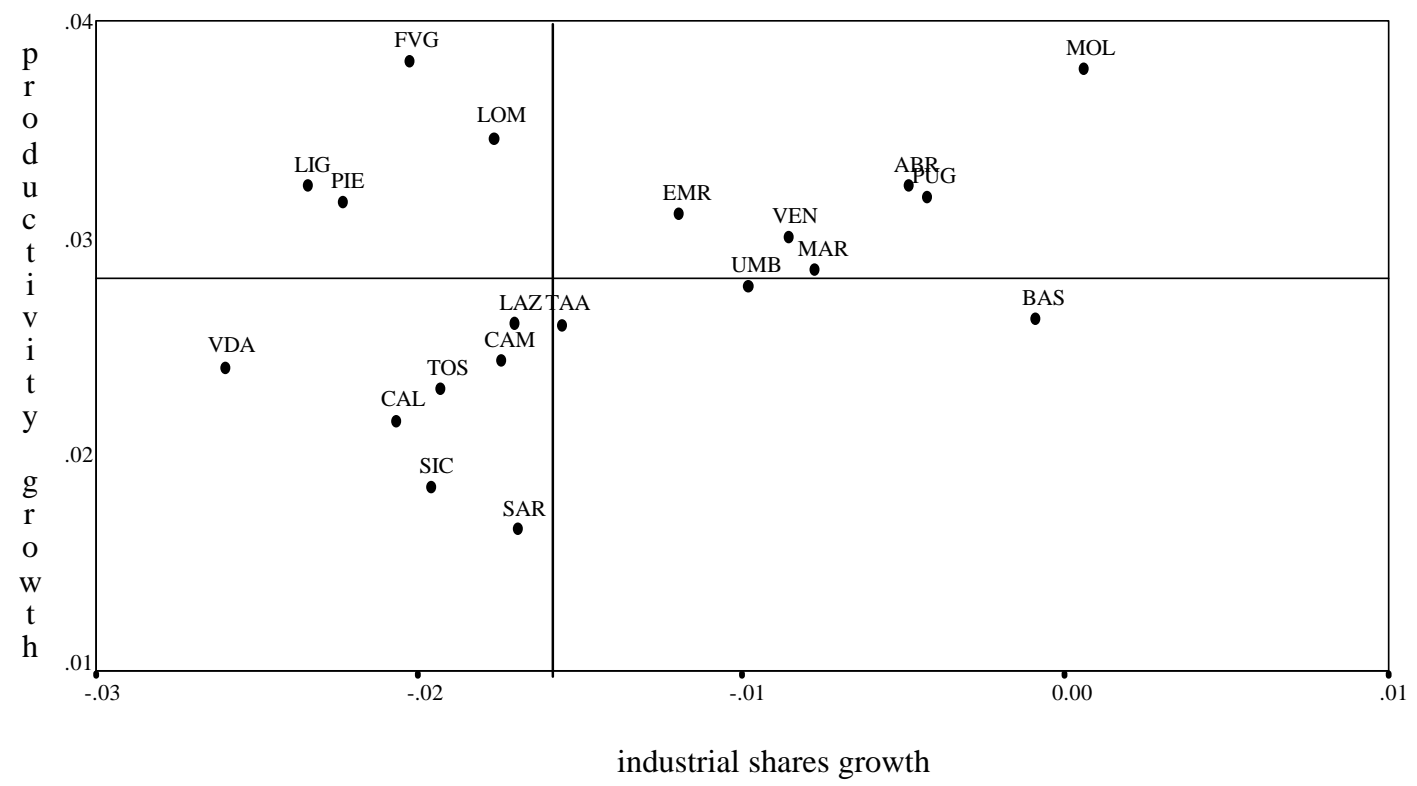

Notes:

growth rates expressed as annual averages

internal line set at the national averages 
Table 1. Distribution dynamics across the Italian regions

\section{A. Labour productivity}

\begin{tabular}{ccccc}
\hline $\begin{array}{c}5 \\
\text { 1951 - 1994 } \\
\text { Initial year }\end{array}$ & $<80$ & $80-95$ & $95-110$ & $>110$ \\
\hline & & & & \\
$<80$ & $\mathbf{0 . 5 0}$ & 0.50 & 0.00 & 0.00 \\
$80-95$ & 0.00 & $\mathbf{0 . 7 1}$ & 0.29 & 0.00 \\
$95-110$ & 0.00 & 0.25 & $\mathbf{0 . 5 0}$ & 0.25 \\
$>110$ & 0.00 & 0.00 & 0.60 & $\mathbf{0 . 4 0}$ \\
& & & & \\
Initial distr. & 0.20 & 0.35 & 0.20 & 0.25 \\
Final distr. & 0.10 & 0.40 & 0.35 & 0.15 \\
\hline
\end{tabular}

\begin{tabular}{crrrr}
$\begin{array}{c}\text { 1951 - 1975 } \\
\text { Initial year }\end{array}$ & $<80$ & $80-95$ & $95-110$ & $>110$ \\
\hline$<80$ & $\mathbf{0 . 2 5}$ & 0.75 & 0.00 & 0.00 \\
$80-95$ & 0.00 & $\mathbf{0 . 4 3}$ & 0.57 & 0.00 \\
$95-110$ & 0.00 & 0.00 & $\mathbf{0 . 7 5}$ & 0.25 \\
$>110$ & 0.00 & 0.00 & 1.00 & $\mathbf{0 . 0 0}$ \\
& & & & \\
Initial distr. & 0.20 & 0.35 & 0.20 & 0.25 \\
Final distr. & 0.05 & 0.30 & 0.60 & 0.05 \\
\hline
\end{tabular}

Final year

\begin{tabular}{crrrr}
$\begin{array}{c}\text { 1975-1994 } \\
\text { Initial year }\end{array}$ & $<80$ & $80-95$ & $95-110$ & $>110$ \\
\hline$<80$ & $\mathbf{0 . 0 0}$ & 1.00 & 0.00 & 0.00 \\
$80-95$ & 0.33 & $\mathbf{0 . 6 7}$ & 0.00 & 0.00 \\
$95-110$ & 0.00 & 0.25 & $\mathbf{0 . 5 0}$ & 0.25 \\
$>110$ & 0.00 & 0.00 & 0.00 & $\mathbf{0 . 0 0}$ \\
& & & & \\
Initial distr. & 0.05 & 0.30 & 0.60 & 0.05 \\
Final distr. & 0.10 & 0.40 & 0.35 & 0.15 \\
\hline
\end{tabular}

\section{B. Per capita income}

\begin{tabular}{ccccc}
\hline \multirow{2}{*}{$\begin{array}{c}\text { 1951 - 1994 } \\
\text { Initial year }\end{array}$} & $<70$ & $70-90$ & $90-110$ & $>110$ \\
\hline & & & & \\
$<70$ & $\mathbf{0 . 8 0}$ & 0.20 & 0.00 & 0.00 \\
$70-90$ & 0.20 & $\mathbf{0 . 4 0}$ & 0.20 & 0.20 \\
$90-110$ & 0.00 & 0.00 & $\mathbf{0 . 4 0}$ & 0.60 \\
$>110$ & 0.00 & 0.00 & 0.00 & $\mathbf{1 . 0 0}$ \\
& & & & \\
Initial distr. & 0.25 & 0.25 & 0.25 & 0.25 \\
Final distr. & 0.25 & 0.15 & 0.15 & 0.45 \\
\hline
\end{tabular}

1951 - $1975 \quad$ Final year

\begin{tabular}{ccccc} 
Initial year & $<70$ & $70-90$ & $90-110$ & $>110$ \\
\hline$<70$ & $\mathbf{0 . 4 0}$ & 0.60 & 0.00 & 0.00 \\
$70-90$ & 0.00 & $\mathbf{0 . 6 0}$ & 0.40 & 0.00 \\
$90-110$ & 0.00 & 0.00 & $\mathbf{0 . 8 0}$ & 0.20 \\
$>110$ & 0.00 & 0.00 & 0.00 & $\mathbf{1 . 0 0}$
\end{tabular}

$\begin{array}{lllll}\text { Initial distr. } & 0.25 & 0.25 & 0.25 & 0.25\end{array}$

\begin{tabular}{lllll} 
Final distr. & 0.10 & 0.30 & 0.30 & 0.30 \\
\hline
\end{tabular}

1975 - $1994 \quad$ Final year

Initial year $\quad<70 \quad 70-90 \quad 90-110 \quad>110$

\begin{tabular}{ccccc}
\hline$<70$ & $\mathbf{0 . 5 0}$ & 0.50 & 0.00 & 0.00 \\
$70-90$ & 0.67 & $\mathbf{0 . 3 3}$ & 0.00 & 0.00 \\
$90-110$ & 0.00 & 0.00 & $\mathbf{0 . 5 0}$ & 0.50 \\
$>110$ & 0.00 & 0.00 & 0.00 & $\mathbf{1 . 0 0}$ \\
& & & & \\
Initial distr. & 0.10 & 0.30 & 0.30 & 0.30 \\
Final distr. & 0.25 & 0.15 & 0.15 & 0.45 \\
\hline
\end{tabular}


Table 2. Labour productivity convergence across the Italian regions

\begin{tabular}{|c|c|c|c|c|c|c|c|c|c|c|}
\hline Periods & Regr. & Costant & $\mathrm{y}_{-1}$ & $\mathrm{BC}$ & $\begin{array}{l}\text { Fixed } \\
\text { effects }\end{array}$ & DS & $\overline{D A}$ & $\mathrm{R}^{2 \text { adj }}$ & $\overline{\mathrm{F}_{\text {test }}}$ & $\overline{\mathrm{DW}_{\text {statistic }}}$ \\
\hline \multirow{5}{*}{$\begin{array}{c}\text { A } \\
1951-94 \\
\text { (860 obs.) }\end{array}$} & A. 1 & & $\begin{array}{c}-0.024 \\
(-13.32)^{\mathrm{a}}\end{array}$ & $\begin{array}{c}0.97 \\
(25.35)^{\mathrm{a}}\end{array}$ & yes & & & 0.53 & 1009.4 & 2.22 \\
\hline & A. 2 & $\begin{array}{c}0.28 \\
(15.54)^{\mathrm{a}}\end{array}$ & $\begin{array}{c}-0.024 \\
(-13.73)^{\mathrm{a}}\end{array}$ & $\begin{array}{c}0.97 \\
(25.45)^{\mathrm{a}}\end{array}$ & no & $\begin{array}{c}-0.004 \\
(-1.96)^{b}\end{array}$ & & 0.54 & 334.7 & 2.20 \\
\hline & A. 3 & $\begin{array}{c}0.27 \\
(15.16)^{\mathrm{a}}\end{array}$ & $\begin{array}{c}-0.023 \\
(-13.40)^{\mathrm{a}}\end{array}$ & $\begin{array}{c}0.97 \\
(25.50)^{\mathrm{a}}\end{array}$ & no & & $\begin{array}{c}0.004 \\
(2.19)^{\mathrm{b}}\end{array}$ & 0.54 & 335.4 & 2.20 \\
\hline & A. 4 & $\begin{array}{c}0.29 \\
(11.89)^{\mathrm{a}}\end{array}$ & $\begin{array}{c}-0.025 \\
(-10.51)^{\mathrm{a}}\end{array}$ & & no & & & 0.16 & 159.9 & 1.93 \\
\hline & A. 5 & $\begin{array}{c}0.28 \\
(15.39)^{\mathrm{a}}\end{array}$ & $\begin{array}{c}-0.023 \\
(-13.52)^{\mathrm{a}}\end{array}$ & $\begin{array}{c}0.97 \\
(25.39)^{\mathrm{a}}\end{array}$ & no & & & 0.53 & 494.7 & 2.19 \\
\hline \multirow{5}{*}{$\begin{array}{c}\text { B } \\
1951-75 \\
(480 \text { obs. })\end{array}$} & B. 1 & & $\begin{array}{l}-0.019 \\
(-5.07)^{\mathrm{a}}\end{array}$ & $\begin{array}{c}0.97 \\
(19.42)^{\mathrm{a}}\end{array}$ & yes & & & 0.51 & 518.4 & 2.29 \\
\hline & B. 2 & $\begin{array}{c}0.25 \\
(7.13)^{\mathrm{a}}\end{array}$ & $\begin{array}{c}-0.021 \\
(-6.01)^{\mathrm{a}}\end{array}$ & $\begin{array}{c}0.97 \\
(19.39)^{\mathrm{a}}\end{array}$ & no & $\begin{array}{l}0.001 \\
(0.21)\end{array}$ & & 0.50 & 164.0 & 2.22 \\
\hline & B. 3 & $\begin{array}{c}0.25 \\
(7.15)^{\mathrm{a}}\end{array}$ & $\begin{array}{c}-0.021 \\
(-6.01)^{\mathrm{a}}\end{array}$ & $\begin{array}{c}0.97 \\
(19.47)^{\mathrm{a}}\end{array}$ & no & & $\begin{array}{l}0.005 \\
(1.61)\end{array}$ & 0.51 & 167.9 & 2.23 \\
\hline & B. 4 & $\begin{array}{c}0.20 \\
(4.38)^{\mathrm{a}}\end{array}$ & $\begin{array}{l}-0.015 \\
(-3.41)^{\mathrm{a}}\end{array}$ & & no & & & 0.09 & 46.6 & 1.88 \\
\hline & B. 5 & $\begin{array}{c}0.26 \\
(7.48)^{\mathrm{a}}\end{array}$ & $\begin{array}{c}-0.021 \\
(-6.28)^{\mathrm{a}}\end{array}$ & $\begin{array}{c}0.97 \\
(19.40)^{\mathrm{a}}\end{array}$ & no & & & 0.51 & 247.5 & 2.22 \\
\hline \multirow{5}{*}{$\begin{array}{c}\mathrm{C} \\
1975-94 \\
(400 \text { obs. })\end{array}$} & C. 1 & & $\begin{array}{c}-0.053 \\
(-8.22)^{\mathrm{a}}\end{array}$ & $\begin{array}{c}0.96 \\
(22.47)^{\mathrm{a}}\end{array}$ & Yes & & & 0.61 & 655.7 & 2.33 \\
\hline & C. 2 & $\begin{array}{c}0.41 \\
(6.46)^{\mathrm{a}}\end{array}$ & $\begin{array}{l}-0.036 \\
(-6.09)^{\mathrm{a}}\end{array}$ & $\begin{array}{c}0.92 \\
(20.66)^{\mathrm{a}}\end{array}$ & No & $\begin{array}{c}-0.008 \\
(-4.12)^{\mathrm{a}}\end{array}$ & & 0.57 & 174.8 & 2.18 \\
\hline & C. 3 & $\begin{array}{c}0.27 \\
(4.94)^{\mathrm{a}}\end{array}$ & $\begin{array}{l}-0.023 \\
(-4.55)^{\mathrm{a}}\end{array}$ & $\begin{array}{c}0.89 \\
(19.88)^{\mathrm{a}}\end{array}$ & No & & $\begin{array}{l}0.004 \\
(2.91)^{\mathrm{a}}\end{array}$ & 0.55 & 162.9 & 2.19 \\
\hline & C. 4 & $\begin{array}{c}-0.00 \\
(-0.01)\end{array}$ & $\begin{array}{l}0.002 \\
(0.25)\end{array}$ & & No & & & 0.03 & 12.1 & 1.99 \\
\hline & C. 5 & $\begin{array}{c}0.27 \\
(4.93)^{\mathrm{a}}\end{array}$ & $\begin{array}{l}-0.023 \\
(-4.50)^{\mathrm{a}}\end{array}$ & $\begin{array}{c}0.88 \\
(19.53)^{\mathrm{a}}\end{array}$ & No & & & 0.53 & 230.2 & 2.14 \\
\hline
\end{tabular}

Notes:

Dependent variable: GDP per worker, annual growth rate.

$\mathrm{y}_{-1}=\log$ GDP per worker, one year lag; $\mathrm{BC}=$ business cycle in Italy; DS = Dummy South; DA = Dummy Adriatic.

Panel estimation: least squares with cross section weights.

t-statistics in parentheses. Significance levels: $a=1 \%, b=5 \%$. 
Table 3. Per capita income convergence across the Italian regions

\begin{tabular}{|c|c|c|c|c|c|c|c|c|c|c|}
\hline Periods & Regr. & Costant & $\mathrm{y}_{-1}$ & $\mathrm{BC}$ & $\begin{array}{l}\text { Fixed } \\
\text { effects }\end{array}$ & DS & DA & $\mathrm{R}^{2 \text { adj }}$ & $\overline{\mathrm{F}_{\text {test }}}$ & $\mathrm{DW}_{\text {statistic }}$ \\
\hline \multirow{5}{*}{$\begin{array}{c}\text { A } \\
1951-94 \\
(860 \text { obs. })\end{array}$} & A. 1 & & $\begin{array}{c}-0.022 \\
(-12.39)^{\mathrm{a}}\end{array}$ & $\begin{array}{c}0.93 \\
(25.96)^{\mathrm{a}}\end{array}$ & Yes & & \multirow{5}{*}{$\begin{array}{c}0.005 \\
(3.09)^{\mathrm{a}}\end{array}$} & 0.54 & 1021.8 & 2.24 \\
\hline & A. 2 & $\begin{array}{c}0.25 \\
(14.89)^{\mathrm{a}}\end{array}$ & $\begin{array}{c}-0.022 \\
(-13.01)^{\mathrm{a}}\end{array}$ & $\begin{array}{c}0.92 \\
(25.89)^{\mathrm{a}}\end{array}$ & No & $\begin{array}{c}-0.011 \\
(-5.47)^{\mathrm{a}}\end{array}$ & & 0.54 & 332.2 & 2.19 \\
\hline & A. 3 & $\begin{array}{c}0.20 \\
(13.10)^{\mathrm{a}}\end{array}$ & $\begin{array}{c}-0.018 \\
(-11.21)^{\mathrm{a}}\end{array}$ & $\begin{array}{c}0.93 \\
(25.63)^{\mathrm{a}}\end{array}$ & No & & & 0.52 & 313.1 & 2.16 \\
\hline & A. 4 & $\begin{array}{c}0.21 \\
(10.32)^{\mathrm{a}}\end{array}$ & $\begin{array}{l}-0.019 \\
(-8.78)^{\mathrm{a}}\end{array}$ & & No & & & 0.12 & 119.0 & 2.05 \\
\hline & A. 5 & $\begin{array}{c}0.21 \\
(13.53)^{\mathrm{a}}\end{array}$ & $\begin{array}{c}-0.019 \\
(-11.51)^{\mathrm{a}}\end{array}$ & $\begin{array}{c}0.93 \\
(25.60)^{\mathrm{a}}\end{array}$ & No & & & 0.52 & 464.7 & 2.14 \\
\hline \multirow{5}{*}{$\begin{array}{c}\text { B } \\
1951-75 \\
(480 \text { obs. })\end{array}$} & B. 1 & & $\begin{array}{c}-0.017 \\
(-4.35)^{\mathrm{a}}\end{array}$ & $\begin{array}{c}0.91 \\
(19.78)^{\mathrm{a}}\end{array}$ & Yes & & \multirow{5}{*}{$\begin{array}{l}0.008 \\
(2.77)^{\mathrm{a}}\end{array}$} & 0.52 & 535.4 & 2.32 \\
\hline & B. 2 & $\begin{array}{c}0.24 \\
(7.22)^{\mathrm{a}}\end{array}$ & $\begin{array}{l}-0.022 \\
(-6.11)^{\mathrm{a}}\end{array}$ & $\begin{array}{c}0.91 \\
(19.70)^{\mathrm{a}}\end{array}$ & No & $\begin{array}{l}-0.007 \\
(-2.09)^{\mathrm{b}}\end{array}$ & & 0.51 & 168.9 & 2.24 \\
\hline & B. 3 & $\begin{array}{c}0.18 \\
(6.55)^{\mathrm{a}}\end{array}$ & $\begin{array}{l}-0.016 \\
(-5.32)^{\mathrm{a}}\end{array}$ & $\begin{array}{c}0.91 \\
(19.80)^{\mathrm{a}}\end{array}$ & No & & & 0.52 & 171.5 & 2.27 \\
\hline & B. 4 & $\begin{array}{c}0.16 \\
(4.34)^{\mathrm{a}}\end{array}$ & $\begin{array}{l}-0.014 \\
(-3.31)^{\mathrm{a}}\end{array}$ & & No & & & 0.07 & 35.9 & 2.02 \\
\hline & B. 5 & $\begin{array}{c}0.20 \\
(7.19)^{\mathrm{a}}\end{array}$ & $\begin{array}{l}-0.018 \\
(-5.85)^{\mathrm{a}}\end{array}$ & $\begin{array}{c}0.91 \\
(19.59)^{\mathrm{a}}\end{array}$ & No & & & 0.51 & 246.9 & 2.23 \\
\hline \multirow{5}{*}{$\begin{array}{c}\mathrm{C} \\
1975-94 \\
(400 \text { obs. })\end{array}$} & C. 1 & & $\begin{array}{c}-0.049 \\
(-9.03)^{\mathrm{a}}\end{array}$ & $\begin{array}{c}0.95 \\
(24.91)^{\mathrm{a}}\end{array}$ & Yes & & \multirow{5}{*}{$\begin{array}{l}0.004 \\
(2.48)^{\mathrm{a}}\end{array}$} & 0.67 & 824.2 & 2.21 \\
\hline & C. 2 & $\begin{array}{c}0.35 \\
(7.10)^{\mathrm{a}}\end{array}$ & $\begin{array}{c}-0.033 \\
(-6.61)^{\mathrm{a}}\end{array}$ & $\begin{array}{c}0.94 \\
(23.41)^{\mathrm{a}}\end{array}$ & No & $\begin{array}{c}-0.019 \\
(-6.66)^{\mathrm{a}}\end{array}$ & & 0.63 & 224.1 & 2.00 \\
\hline & C. 3 & $\begin{array}{c}0.10 \\
(3.11)^{\mathrm{a}}\end{array}$ & $\begin{array}{l}-0.008 \\
(-2.46)^{\mathrm{a}}\end{array}$ & $\begin{array}{c}0.95 \\
(22.54)^{\mathrm{a}}\end{array}$ & No & & & 0.60 & 197.9 & 1.89 \\
\hline & C. 4 & $\begin{array}{l}0.059 \\
(1.29)\end{array}$ & $\begin{array}{l}-0.004 \\
(-0.87)\end{array}$ & & No & & & 0.02 & 8.84 & 1.81 \\
\hline & C. 5 & $\begin{array}{c}0.10 \\
(3.20)^{\mathrm{a}}\end{array}$ & $\begin{array}{l}-0.008 \\
(-2.50)^{\mathrm{a}}\end{array}$ & $\begin{array}{c}0.95 \\
(22.32)^{\mathrm{a}}\end{array}$ & No & & & 0.59 & 284.6 & 1.86 \\
\hline
\end{tabular}

Notes:

Dependent variable: GDP per capita, annual growth rate.

$\mathrm{y}_{-1}=\log$ GDP per capita, one year lag; $\mathrm{BC}=$ business cycle in Italy; DS = Dummy South; DA = Dummy Adriatic.

Panel estimation: least squares with cross section weights.

t-statistics in parentheses. Significance levels: $a=1 \%, b=5 \%$. 
Table 4. Productivity growth and sectoral dynamics across the Italian regions. 1960 - 1994

\begin{tabular}{|cccccccc|}
\hline Regr. & NAS $_{-1}$ & $\mathrm{y}_{-1}$ & DNAS & $\begin{array}{c}\text { Fixed } \\
\text { effects }\end{array}$ & $\begin{array}{c}\text { Temporal } \\
\text { effects }\end{array}$ & $\mathrm{R}^{2 \text { adj }}$ & $\mathrm{F}_{\text {test }}$ \\
\hline 1 & $\begin{array}{c}-0.15 \\
(-5.18)^{\mathrm{a}}\end{array}$ & & & Yes & Yes & 0.49 & 13.1 \\
& -0.05 & -0.14 & & Yes & Yes & 0.54 & 15.6 \\
2 & $(-1.75)^{\mathrm{c}}$ & $(-8.46)^{\mathrm{a}}$ & & & & & \\
3 & -0.04 & -0.13 & -0.07 & Yes & Yes & 0.54 & 15.5 \\
& $(-0.84)$ & $(-8.15)^{\mathrm{a}}$ & $(-2.47)^{\mathrm{b}}$ & & & & \\
\hline
\end{tabular}

Notes:

Dependent variable: GDP per worker, annual growth rate.

$\mathrm{y}_{-1}=\log$ GDP per worker, one year lag.

$\mathrm{NAS}_{-1}=$ non agriculture labour share, one year lag.

DNAS $=1960-75$ equals NAS, 1976-94 equals 0.

Panel estimation: least squares dummy variables.

Number of observations: 680.

$\mathrm{t}$-statistics in parentheses. Significance levels: $\mathrm{a}=1 \%, \mathrm{~b}=5 \%, \mathrm{c}=10 \%$. 